(C) 2015, Elsevier. Licensed under the Creative Commons Attribution-NonCommercial-NoDerivatives 4.0 International

http://creativecommons.org/licenses/by-nc-nd/4.0/

Manuscript Number: CAIE-D-12-00938R2

Title: Holonic Supply Chain: A study from Family-Based Manufacturing Perspective

Article Type: Research Paper

Keywords: Supply Chain Coordination; Discrete Event Simulation; Average Flow Time; Family-Based Dispatching; Holonic Paradigm

Corresponding Author: Dr. Navin K. Dev, Ph.D.

Corresponding Author's Institution: Dayalbagh Educational Institute

First Author: Navin K. Dev, Ph.D.

Order of Authors: Navin K. Dev, Ph.D.; Navin K Dev, Ph.D.; Ravi Shankar, Ph.D.; Prasanta K Dey, Ph.D.; Angappa Gunasekaran, Ph.D.

Abstract: In the contemporary business environment, to adhere to the need of the customers, caused the shift from mass production to mass-customization. This necessitates the supply chain (SC) to be effective flexible. The purpose of this paper is to seek flexibility through adoption of family-based dispatching rules under the influence of inventory system implemented at downstream echelons of an industrial supply chain network. We compared the family-based dispatching rules in existing literature under the purview of inventory system and information sharing within a supply chain network. The dispatching rules are compared for Average Flow Time performance, which is averaged over the three product families. The performance is measured using extensive discrete event simulation process. Given the various inventory related operational factors at downstream echelons, the present paper highlights the importance of strategically adopting appropriate family-based dispatching rule at the manufacturing end. In the environment of mass customization, it becomes imperative to adopt the family-based dispatching rule from the system wide SC perspective. This warrants the application of intra as well as inter-echelon information coordination. The holonic paradigm emerges in this research stream, amidst the holistic approach and the vital systemic approach. The present research shows its novelty in triplet. Firstly, it provides leverage to manager to strategically adopting a dispatching rule from the inventory system perspective. Secondly, the findings provide direction for the attenuation of adverse impact accruing from demand amplification (Bullwhip effect) in the form of inventory levels by appropriately adopting family-based dispatching rule. Thirdly, the information environment is conceptualized under the paradigm of Koestler's holonic theory. 
Cover Letter

Dear Prof. Dessouky,

Please consider our revised manuscript \# CAIE-D-12-00938R1 entitled "Holonic Supply Chain: A study from Family-Based Manufacturing Perspective" in your esteemed journal - Computers and Industrial Engineering.

We have responded all the queries/suggestions made by the esteemed reviewers.

Best Regards 


\title{
Holonic Supply Chain: A study from Family-Based Manufacturing Perspective
}

\author{
Navin K. Dev* \\ Department of Mechanical Engineering, \\ Dayalbagh Educational Institute, \\ Dayalbagh, Agra, INDIA \\ Email: navinkumardev@yahoo.com
}

\section{Ravi Shankar}

Department of Management Studies, Indian Institute of Technology Delhi,

New Delhi, INDIA

Email: r.s.research@gmail.com

Prasanta K. Dey

Operations and Information Management Group,

Aston Business School,

Birmingham, U.K.

Email: p.k.dey@aston.ac.uk

\section{Angappa Gunasekaran}

Department of Decision and Information Sciences, University of Massachusetts,

Dartmouth, USA

Email: agunasekaran@umassd.edu 


\section{Highlights}

- We analyze the impact of inventory system on family dispatching rule.

- Appropriate family dispatching rule have mitigation effect on demand amplification.

- The information is conceptualized under the paradigm of Koestler's holonic theory.

- For an industrial case, analysis of dispatching rules is performed from total supply chain perspective.

- Family dispatching rules are compared for Average Flow Time performance. 
To

Prof. Dessouky,

Editor-in-Chief, Computers and Industrial Engineering

Manuscript ID CAIE-D-12-00938R1 entitled "Holonic Supply Chain: A Study from FamilyBased Manufacturing Perspective”

Dear Prof. Dessouky,

We greatly appreciate the valuable comments/suggestions provided for our paper by the esteemed reviewers. We have modified the manuscript by incorporating the changes advised by the reviewers as mentioned below.

1. The explanation for conclusion "the findings indirectly indicate the mitigation of effect of demand amplification (Bullwhip effect) by appropriately adopting family-based dispatching rule" is not intelligible enough. It is suggested that the authors provide further explanation regarding lower Average Flow Time results in mitigation of Bullwhip effect.

We appreciate the suggestion made by the reviewer. In the revised manuscript we have incorporated a paragraph on page 12 and 13, para 4 that read as ..... "As mentioned in Section 4.3, we have assumed forecast demand higher than the realized demand. As a result, the orders to the immediate upstream............... Alternatively, to get a better feel of it we carried out another simulation experiment............ However, to address the issue of extent by which the effect of demand amplification or bullwhip effect can be mitigated by adopting a specific FBD rule could be the subject for future research".

2. The measure unit should be marked in Figure 6-10.

We appreciate the observation made by the reviewer. We have incorporated the units of measures in the Figures from 6 through Figure 10.

3. There are spelling mistake in the paper, such as "While at one extreme of coordination aspect we considered information of back orders, at the other end of the continuum of information coordination we consider a situation in which each echelon "forecast" its demand (the practice being adopted by the supply chain under study)" in Section 3.2. "Forecast" should be "forecasts". So please check the paper again to eliminate these flaws.

We apologize for the inconvenience and thankful for pointing out the errors in spellings and other flaws in sentences. We have checked and made rectifications throughout the revised paper. 
Once again, we greatly appreciate the very constructive and meticulous inputs / suggestions / observations of the Editor-in-Chief and the esteemed reviewers. We now eagerly look forward to your response on our revised manuscript.

With warm and best regards 


\title{
Holonic Supply Chain: A study from Family-Based Manufacturing Perspective
}

\begin{abstract}
In the contemporary business environment, to adhere to the need of the customers, caused the shift from mass production to mass-customization. This necessitates the supply chain (SC) to be effective flexible. The purpose of this paper is to seek flexibility through adoption of familybased dispatching rules under the influence of inventory system implemented at downstream echelons of an industrial supply chain network. We compared the family-based dispatching rules in existing literature under the purview of inventory system and information sharing within a supply chain network. The dispatching rules are compared for Average Flow Time performance, which is averaged over the three product families. The performance is measured using extensive discrete event simulation process. Given the various inventory related operational factors at downstream echelons, the present paper highlights the importance of strategically adopting appropriate family-based dispatching rule at the manufacturing end. In the environment of mass customization, it becomes imperative to adopt the family-based dispatching rule from the system wide SC perspective. This warrants the application of intra as well as inter-echelon information coordination. The holonic paradigm emerges in this research stream, amidst the holistic approach and the vital systemic approach. The present research shows its novelty in triplet. Firstly, it provides leverage to manager to strategically adopting a dispatching rule from the inventory system perspective. Secondly, the findings provide direction for the attenuation of adverse impact accruing from demand amplification (Bullwhip effect) in the form of inventory levels by appropriately adopting family-based dispatching rule. Thirdly, the information environment is conceptualized under the paradigm of Koestler's holonic theory.
\end{abstract}

Key words: Supply Chain Coordination; Discrete Event Simulation; Average Flow Time; Family-Based Dispatching; Holonic Paradigm

\section{Introduction}

In the contemporary business environment, to adhere to the need of the customers, whose role has changed from a consumer to prosumer, that is, the saturation of markets with standardized products have pushed the customer towards the search for higher levels of differentiation and personalization of products. This behavior of customer has lead to an environment where most manufacturing companies shift from mass production to mass-customization (Dominici, 2008). Further, the manufacturing companies have realized that their performance with specific goals cannot be met adequately if operated in isolation. The spread of IT technology made it possible for the firms to seamlessly access the knowledge base, communicate, and negotiate with other echelon, which are autonomous with specific goals and resources. The ability to respond to customer orders in a timely fashion can provide a critical competitive advantage. These challenges warrant the needs for agility that are able to: a) suitably react to the market environment's instability; b) coordinate production system through the adoption of IT technologies; c) continuously examine the existing operational units for adaptive decisions so as to harness high level of performance measures. 
The above challenges of coordination can be viewed in the purview of theories on living organisms and social organizations, which, if applied to the business, present a representation of the firm as a living system. The holonic paradigm emerges in this research stream, amidst the holistic approach and the vital systemic approach. The holonic paradigm stems from the thoughts of (Koestler, 1967) who underlined how complex systems can originate only if they are composed of stable and autonomous sub-systems, which are able to survive turbulences and, at the same time, can cooperate forming a more complex system. Koestler suggests that analyzing both the biological and the physical universe shows that, it is necessary to take into account the relations between the whole and the part of the entity we observe. The term holon is a combination of the ancient Greek word 'holos' with the meaning of 'whole' and the suffix meaning 'entity' or part. The holon is, indeed, a whole which includes, simultaneously, the elements or the sub-parts which form it and give it structural and functional meaning. Holons act as intelligent, autonomous and cooperative entities working together inside hierarchies called 'holarchies'. A holarchy is a hierarchy of self-regulating holons working, in coordination with their environment, as autonomous wholes which are hierarchically superior to their own parts and, at the same time, are parts dependent with the control of superior levels. Figure 1 shows the general relationship between holon and holarchy. Holons of the same level process elements and information coming from lower level holons and they transfer the results to higher level ones for further processing. Processes of holons belonging to level ' $n$ ' hence originate from process of ' $n-1$ ' level subordinated holons and at the same time are the input for the processes of ' $n+1$ ' superior holons (Dominici, 2008).

In consistence to holonic theory, flexibility cannot be considered in only one single echelon of a supply chain. An improvement in the flexibility of an entire supply chain (SC) is necessary to harness high level of performance results (Christopher \& Towill, 2001). Flexibility must be the inherent property of the firm to be agile. To attain a high level of supply chain flexibility (SCF), a strategic supply chain network has to be used to build up specific flexibility potential. Winkler (2009) distinguished these potential as: i) structural, and ii) technological. Structural potential concerns designing the virtual organizations that enable a broad modularization in a supply chain. Thus customer orders can be routed through the supply chain network partners. This attribute of strategic supply chain network is called the 'liberty of orders' that ensures the selected partners can independently handle specific parts of customer's orders, in which they are fully responsible for order's fulfillment (Lau \& Yam, 2005).

\section{Pl. Insert Figure 1 about here}

Further, the increasing complexity of intelligent manufacturing systems has stimulated development of an emerging technology. This evolving technology paradigm is called Holonic Manufacturing Systems (HMS). The rational for needing HMS technology is that it represents a novel paradigm for addressing some of the most critical problems encountered as manufacturing businesses. These include (i) supporting product variety (mass customization) within a single shop floor, (ii) short 'order-to-delivery' times, and (iii) integrating supply chains to hold minimal reserve stocks.

Within the purview of above potentials, researchers remain incisive for functionalities beyond the boundaries of manufacturing; it could obtain better competitive edges if it were, gathering external partners that do some tasks in better ways than it ordinarily does by itself. Hence, the virtual enterprises (VE) within a supply chain network, was a natural result of HMS 
(Georges et al., 2009). VE refers to a temporary alliance of enterprises that come together to share skills or core competencies and resources in order to better respond to business opportunities, and whose cooperation is supported by computer networks (Goletz \& Ferreira, 2000). Sihn (1998) states that a VE combines various companies while maintaining the greatest possible flexibility and business independence. Huang et al. (2002) have developed a holonic framework for virtual enterprises. The planning of VE activities was carried out by a set of holons while scheduling is executed autonomously by each partner enterprise.

Technological potential is concerned with information technologies. Information sharing among various echelons of a supply chain is an important prerequisite for the realization of its flexibility potentials. Information system supports the integration of partners and liberty of orders in the strategic supply chain network. The information system of a strategic supply chain network bears the characteristic to share information between all the partners of the value-added processes. With a high degree of versatility of the resources used, it is very useful to cooperate with some partners that hold needed resources in the strategic supply chain network (Kara \& Kayis, 2004). This leads to 'plug and produce' system for order processing, means that partners are connected swiftly through logistics intrinsically.

The present study is motivated by undertaking a case study of a manufacturing firm situated in Haryana, India. The manufacturing firm is engaged in production of oil pumps, clutches, and sprockets for various automobiles like motorcycles, scooters, three-wheelers, mopeds and stationary engines such as generator sets. The firm is extensively involved in outsourcing some of their machining of turned components viz', main jet, needle jet, air adjuster, emulsion tube, valve seat, and bush valve seat to three local manufacturers located at an arm's distance. These local manufacturers are connected logistically to the concerned company in a very swift manner. Typically, we can refer to these local manufacturers as VEs. Each of these VE is equipped with CNC Turning centers that are capable of machining any of the above mentioned components. It was observed that the machining of the components at these VEs was carried out solely on the first come first serve basis. This required a major set-up time for switching from one type of component to the other. Set-up time includes loading the raw material, arranging clamping fixtures, uploading the NC program, and placing the required tools into the tool carousel. We further observed that these components can certainly be grouped into families, according to their shape and sequence of operations required. Thus, we segregated the above components into three families.

Picking up on this lead, we associate the case study to the notions of virtual cell manufacturing (VCM) under the purview of structural and technological potentials discussed above. VCM starts from the idea that grouping efficiencies can be realized using family-oriented scheduling/dispatching rules (Kannan \& Ghosh, 1996). Rules for family-based dispatching (FBD) are made assuming a two-phase approach, in which the choice of a family precedes the choice of a specific job-from the set of jobs available for the family (Mosier et al. 1984). Essentially, alternative rules for family-based dispatching only differ with respect to family priority setting. These rules strive to improve lead time performance by reducing set-up time. This is realized by grouping products that share similar requirements with respect to system setup, i.e. families, for joint dispatching. The surrogate measure of lead time is the Flow Time performance. In literature, most of the definitions for family priority setting are driven by the experimental factors considered autonomously at the manufacturing end (Nomden et al., 2008). In such a case, the issue of FBD rules raises a question such as: 
- Has the strategic adoption of specific FBD rule been adequate for enhancing Flow time performance when manufacturing entity operates in isolation to system wide business organization?

From a managerial point of view, given the high degree of intrinsic structural and technological $\mathrm{SCF}$, to deal with the mass customization environment, it is important to understand the effect of FBD rules on Flow Time performance from the integrated SC system perspective.

In view of above, the present paper contributes to the knowledge of the benefit of familybased dispatching (FBD) rules from the total SC perspective. The FBD rules are analyzed addressing the issue of Average Flow Time performance in the presence of operational parameters, especially associated with inventory and information sharing systems adopted at various echelons (holons) of the supply chain network of the firm under study. The Average Flow Time performance is measured at the VEs by averaging over the entire product families. To keep the results tractable, we limit ourselves to two dispatching rules mentioned in the literature: First come family (FCFAM) and Minimum average set-up time (MAS), while the complexity is considered in inventory system and SC structure. FCFAM rule shows similarities with the well known first come first serve rule (FCFS). It prioritizes families by considering the earliest entry moment of the jobs available in the queue for a family. MAS relates to the priority decision based on family set-ups to the respective number of items in queue. In the anticipation of the benefit of dispatching rules towards the reduction of Average Flow Time, we carried out extensive simulation.

This paper is structured as follows. In Section 2 we survey the literature and outline our research contributions. Section 3 demonstrates the supply chain network description of the firm under study in terms of the decision making process at various echelons, and inventory control procedure. To realize the potential of alternate FBD rules in the purview of various inventory related operational settings at holarchy levels, we conducted extensive simulation. The simulation design for various factors is explained in Section 4. Simulation results and its discussion are discussed in Section 5 and 6 respectively. Finally, conclusions are summarized in Section 7.

\section{Literature review}

The literature contains a diverse range of interpretations of Koestler's concepts for manufacturing. The application of these ideas was first studied by Suda (1989), who discussed the dynamic organizational structure of a highly automated holonic manufacturing system. The Japanese initiative on Holonic Manufacturing involves a multi-national collaborative research activity under Intelligent Manufacturing Systems (IMS) programme. This collaborative effort also involves several Japanese companies, namely Hitachi Ltd., Toshiba Corp., Yaskawa Electric, Fanuc and Hitachi Seiko. The ultimate aim is to develop a solution for high variety and variable batch size manufacture through the development of architecture for highly decentralized manufacturing systems, built from a modular mix of autonomous, cooperative and intelligent elements (Van Brussel et al. 1995; Fletcher et al. 2000; Kotak et al. 2003). A framework for modeling virtual enterprises using the holonic approach is presented by Huang et al. (2002) wherein each VE holon has four corresponding sub-holons, planning, scheduling, task and resource holons. Resource holon further comprises factory, shop-floor, workstation and cell holons. Although there are many instances of the application of holonic manufacturing, this paper demonstrates the issue of application of holonic paradigm applied for modeling of supply chain network. The impetus for the development of modeling through holonic approach is due to 
the increasing need of system wide coordination in SC network as in the existing competitive market, there is no one single organization that could respond to the need of providing products and services independently. Thomas and Griffin (1996) and Narasimhan and Carter (1998) believe that efficient management and appropriate integration of an SC entails coordination of product and information among suppliers, manufacturer, and the customer. Chen et al. (1998) and Vernadat (1997) suggested solving these problems through the involvement of virtual enterprises that quickly provide the right information to the right place, at the right time, and with the right format. Fernando and Sichman (2010) developed a theoretical model that combines a constraint network approach and a holonic multi-agent approach to support coordination and management of a typical oil industry supply chain.

Mass customization and increasing competition force manufacturers in various industries towards higher level of responsiveness. Group technology provides one of the answers to meet these demands. The key idea underlying this concept is the exploitation of similarities in product and process design that result in the study of family-based dispatching rules for shop floor control (Mahmoodi et al. 1992; Frazier, 1996; Mahmoodi \& Martin, 1997). Kanan and Ghosh (1996) proposed two 'look-ahead' dispatching schemes called VCM3 and VCM5. Both rules start from the idea that the operator is informed about the set of families which, next to having one or more jobs in the queue, also have jobs being processed in a preceding machine. Nomden et al. (2008) studied family-based dispatching rules taking information technology into account. While prioritizing they consider the queue length of the family, which is yet to arrive according to information provided to the downstream machine operator. Hamedi et al. (2012) suggested capability-based Virtual Cellular Manufacturing System. They developed Goal Programming model in which parts, machines, and workers are grouped and showed the efficient utilization performance. Ko et al. (2010) suggested the job dispatching rule based on product quality index and simultaneously focused on meeting due dates. Van der Zee (2013) considered FBD based on batch availability in shop i.e., the jobs of same batch become available for processing and leave the machine together. The author compared the proposed rule with existing exhaustive and nonexhaustive rules in literature. The outcomes of the simulation study found that proposed extended rule has improved system performance in terms of Flow time.

However, most of the family-based studies are driven by the assumptions confined to shop floor or by the manufacturing oriented parameters. In contrary to it, the contemporary business environment does not allow any entity of the value chain to operate in isolation for enhancing the system wide performance.

The potential of supply chain responsiveness towards mass customization in order to minimize the Average Flow Time largely depends on the agility or the flexibility of the supply chain. Managing agility in the supply chain has never been as challenging as it is today. Supply chain risks are inherited in different kinds like natural disaster, terrorist attack, labor strike and accidents. These can all be the causes for supply chain disruption and delay (Christopher \& Lee, 2004; Tang, 2006). Delay does not only halt the supply chain operations, but without preparation and precaution, it takes time for the affected system to recover (Sheffi \& Rice, 2005). Inventory management is an effective way of dealing with such disruption situations. A plethora of literature is available dealing with inventory during supply disruptions (Gupta, 1996; Lewis, 2005). However, study of inventory systems in real stochastic supply chains is one of the major concerns in today's supply chain management. As soon as the number of parameters affecting supply chain performance becomes high and the objective becomes the whole supply chain analysis, simulation plays a more critical role in finding the optimal trade-off among the 
involved variables (inventory policies, lead times, demand patterns, customers' satisfaction) as reported in Chang and Makatosoris (2001). To this end the Modelling and Simulation-based approach is jointly used with statistical techniques such as Design of Experiment and Analysis of Variance (Longo et al., 2005; Suwanruji \& Enns, 2006). The state-of-the-art overview highlights that Modelling and Simulation in combination with statistic techniques is usually used for analyzing supply chain scenarios (Sensi et al., 2008).

Further, it is well-acknowledged in the supply chain literature that information sharing and physical flow coordination can lead to enhanced supply chain performance (Chen, 1998; Cachon $\&$ Fisher, 2000). Sahin \& Robinson (2002) reported comprehensive surveys of the supply chain information sharing and coordination literature. Wadhwa et al. (2008) highlighted the observations regarding cooperation and information transparency in the supply chain. The authors mentioned that even under the conditions of stock-out inventory the customer requires a certain degree of reliability from the enterprise towards fulfillment of stock-out demand. Such is a typical case of a concern for the agile enterprise. These enterprises, under such stock-out condition eventually needs to fulfil the demand through cooperative mechanism. Dev et al. (2011, 2012(a)) suggested sharing of demand information across various echelons of supply chain network for the performance improvement over the entire supply chain.

In view of above, we attempt to fill a gap by associating the real industrial case and realizing various issues from the following viewpoint.

(i) The potential of flexibility of manufacturing system is analyzed through FBD rules from the total supply chain perspective.

(ii) The complexity of manufacturing system is viewed from the application of Koestler's holonic concept.

(iii) While comparing FBD rules, the shop floor load is realized through the stochastic behavior of supply chain disruptions affecting inventory system of downstream echelons.

(iv) The impact of information coordination of FBD rules are investigated from a supply chain perspective.

Therefore, with the above necessary analysis, for which there is little to no literature exist, we foresee that the present paper provides a sound and an insightful basis for exploring the relevance of assumed FBD rules from the view point of total supply chain. The SC network of the firm under study is analyzed for the Average Flow Time performance over the assumed number of product families under the purview of inventory system and informational coordination.

\section{Supply chain network description of the firm}

Although the manufacturing firm was engaged in the production and distribution of several engineering components for the automobile industry, we specifically carried out the study of the supply chain of the components mentioned in Section 1 so as to keep our motive of study focused to analyze FBD rules at VEs (the local manufacturers). The firm supplies its manufactured products to reputed original equipment manufacturers (OEMs) that cover a large sector of automobile industry in India. They also supply the components to the open market through product warehouse and retailers. The supply to the OEMs is well established in terms of supply volumes and lead time commitments on account of contractual agreements. However, distribution on the open market is typically subject to the uncertainties and was therefore chosen as the focus for this case study. It was decided to focus on the distribution network within the 
given city for the sake of model tractability. This does not sacrifice our main focus of study to analyze the performance of alternative FBD rules at VEs from total supply chain perspective. The focal manufacturing firm (M) supplies the components to their warehouse (W) which caters the demand of three retailers (R1, R2 and R3) as shown in Figure 2. The performance is measured at three VEs associated with the focal firm under study with a high degree of intrinsic logistics capabilities. In our study system of supply chain network, we compared two FBD rules, FCFAM and MAS for the operational performance, Average Flow Time. Further, each of the three distinct retailers experience same demand patterns of three product families, each of which are exponentially distributed with same mean value. This positively appends to the analysis as it would illustrate the impact of inventory related parameters on two different FBD rules. We now discuss various structural and informational systems at various echelons.

\section{Pl. Insert Figure 2 about here}

\subsection{A framework for decision making at echelons}

As the performance measure, Average Flow Time over the entire families is measured at VEs for two different FBD rules. Therefore, it is expedient to discuss first the framework for FBD rules at VEs. We assume that the focal manufacturer sends its orders to VEs (sub-manufacturers) according to predefined product family. We further assume a centrally operated controller, viewed as a holon that manages the order dispatching to VEs. Based upon the ordering policy adopted by the focal manufacturer, each of the three product families are randomly ordered for any of the two pre-defined VEs for its processing. For an instant, jobs of family 1 are processed at VE1 \& VE2, family 2 is processed at VE2 \& VE3, and VE3 \& VE1 are pre-selected for processing family 3 . This means, each VE is assumed to be capable of processing two families of products. We distinguish the framework between performance criterion, information criterion and decision options.

(i) Performance criterion - We consider the minimization of Average Flow Time over all the three families $(M F T)$ in the finite simulation run. Average Flow Time per job is defined as:

$$
M F T=\frac{\sum_{j \in J} \sum_{i=1,2, \ldots} f t_{i, j}}{N} \text { with } f t_{i, j}=w_{i, j}+p_{i, j}
$$

where job ' $i$ ' belonging to family ' $j$ ' $\left(f t_{i, j}\right)$ we distinguish between waiting time $\left(w_{i, j}\right)$ and job processing time $\left(p_{i, j}\right)$.

(ii) Information Criterion - We consider the different perspectives of information:

- Local data, like queue lengths per family, family set-up times and job processing times.

- Back order information, that is, we consider an information aspect that provides a high degree of flexibility in the analysis of Average Flow Time in case of family dispatching criteria. We propose a holonic agent that monitors the back orders at downstream echelons (focal manufacturer and warehouse). While comparing the assumed FBD rules for prioritizing the processing, the quantity of back orders belonging to the same family at the downstream echelons is taken into account. We assume an information delay in acquiring the quantity of back orders and consider it as an experimental factor. This kind of informational aspect supports the indications of high degree of flexibility proposed by Wadhwa et al. (2008) in which the authors mentioned that reliability towards fulfillment of stock-out demand can be enhanced through coordination.

(iii) Decision Options - Essentially a dispatcher have a few decision options available for triggering the family batches for the processing on machine: 
- Switch the machine set-up to meet the requirements of another family, according to the availability of machine and comparing two families at a VE for a minimum average set-up time in case of the MAS prioritizing model. Switching to different family constitute a delay time due to a major set-up time $s_{j 0, j}$. The length of the major set-up time is determined by averaging over the minor setups related to each job of the family in queue constituting a batch. If the major set-up time for the current set-up - for family $j_{0}$ - and the required set-up for family $j$, then apparently, $s_{j 0, j}=0$ for $j=j_{0}$. Products related minor set-ups are assumed to be normally distributed.

Let us now discuss the information criterion and decision options at downstream echelons; focal manufacturer, warehouse and retailers which are typically maintained and controlling the inventories of product families that are routed through the supply chain. We reiterate that in the present paper various inventory variables are the experimental factors, the impact of which is analyzed for Average Flow Time performance under the two FBD rules: FCFAM and MAS. We would like to mention here that the focal manufacturing organization under study is not equipped with any informational capability (e.g. EDI) setup of effecting seamless operational data exchange throughout the network. Basically, their ordering operations at each echelon entail three distinct sub-operations comprising of (i) Sales, (ii) Product storage; and (iii) Inventory Control Management. In the present paper the proposed setup view these distinct operations as sub-holons of a larger holon (echelon) having informational coordination. These sub-holons interact in real-time for processing of orders to be placed in the immediately preceding echelon member. Under information criterion, Figure 3 schematically shows the various operations performed by each downstream echelon while effecting ordering decisions in the supply chain network structure.

\section{Pl. Insert Figure 3 about here}

Informational and decision operations at various sub-holons include:

Sales sub-holon

- Receiving of orders from downstream echelon (customers in case of Retailers).

- Product disposal information to storage on getting inquiry about the availability of products.

- Orders to upstream echelon for inventory replenishment.

Product Storage sub-holon

- Disposal of products to the downstream echelon on receipt of orders from sales (to the customers in case of Retailers).

- Providing information to sales and the inventory controller about the current inventory levels.

Inventory control management sub-holon

- Computes the orders according to the inventory control system under experimental design. The order placed is based upon:

- The information from sales about the orders in-process; and

- The information from storage about the number of products in storage inventory.

- Sends information to sales for ordering to upstream echelon. 


\subsection{Inventory control procedure}

To ensure sufficient product inventory at the individual echelon stock points, each distinct echelon member of the firm under study adopts a conventional $(s, S)$ inventory control procedure (also called Min-Max Inventory Control Policy in the literature) operating in a periodic review mode. Here, 's' is the re-order point, while the ' $S$ ' is the order-up-to level (Olhager \& Persson, 2006). After receipt of a demand order, each retailer checks his product storage inventory, and if there is adequate inventory in store, demand is fulfilled completely. Else, the demand ordered is partially fulfilled from the inventory in stock, and the remaining amount is backordered. The backordered quantity is then replenished in a first-in, first-out (FIFO) manner. In the present study, we consider the back orders under the purview of informational coordination for the FBD batch operations. While at one extreme of coordination aspect we considered information about back orders, at the other end of the continuum of information coordination we consider a situation in which each echelon forecasts its demand (the practice being adopted by the supply chain under study). The forecast demand is assumed higher than the realized demand due to the

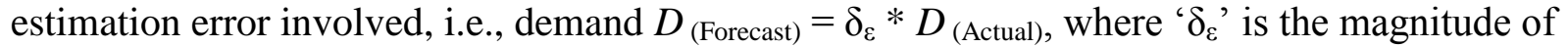
the assumed forecasting error (Masuchun et al., 2004). We also paid attention to its sensitivity towards the Average Flow time while comparing FCFAM and MAS.

\section{Design of simulation study}

A simulation study was designed to compare the strategic adoption of alternative FBD rules: FCFAM and MAS. In this section we discuss the experimental design by describing alternative configuration of VEs and inventory control system at downstream echelons: focal manufacturer, warehouse and retailers. As discussed in Section 3.1 and 3.2 about various informational and decision criteria at VEs and downstream echelons, the SC system in the present paper can be viewed from the holonic paradigm perspective in consistent to Winkler (2009) shown in Figure 4. Various echelons of assumed supply chain network at level (n) acts as the holons operating autonomously in managing their operational units, i.e. sales, product storage and inventory control management systems at level (n-1). These autonomous holons are under the holarchy of the supply chain of a total business system at the level $(n+1)$. Further, the information was realized at intra-holon level wherein various operational units share the information discussed in Section 3.1. In case of Inter-holon information controller, we reiterate our assumption that an information controlling holon monitors the back orders of downstream echelons (focal manufacturer and warehouse) and sends orders to corresponding VE associated with family processing. At each VE, in case of MAS dispatching rule, the dispatching causes once the jobs are available in two pre-specified family queues. The algorithm used in the simulation is shown in Figure 5.

\section{Pl. Insert Figure 4 about here}

\section{Pl. Insert Figure 5 about here}

\subsection{Experimental design}

A simulation model of the four-echelon supply chain network structure was developed in the Arena ${ }^{\circledR}$ simulation language (Kelton et al., 2010). The External Visual C++ code was linked into the Arena models to capture the inventory control logic utilized in the simulation model. Also, 
since simulation in Arena ${ }^{\circledR}$ involve samples from probability distributions (e.g., for customer demand, lead times and their standard deviations, etc.), it is recommended that a requisite number of replications of a sufficiently long duration (in order to eliminate the initial transient bias) be carried out in order to justify the normality assumption required for the statistical interpretation of simulation results. In our experiments, therefore, the simulation models were run for 10,000 simulation minutes (approx. seven days) each with 10 replications which was found adequate for analysis purposes. The performance measure of interest was Average Flow Time averaged over assumed three product families.

To study the impact of the assumed factors within the supply chain network structure, as a starting point for discussing the experimental design we adopt table 1. It specifies fixed and experimental factors.

\begin{tabular}{|c|c|}
\hline \multicolumn{2}{|l|}{ Fixed Factors } \\
\hline No. of families & 03 \\
\hline Holarchy levels (No. of Echelons) - 04 & $\begin{array}{l}\text { 3-Retailers; } \\
\text { 1-Warehouse; } \\
\text { 1-Focal Manufacturer; } \\
\text { 3-VEs }\end{array}$ \\
\hline Demand at 3-Retailers (D) & Time between Arrival $=\operatorname{EXPO}(0.5)$ \\
\hline Minor Set-up time distribution & $\operatorname{NORM}(5,0.2)$ \\
\hline Processing time distribution & $\operatorname{NORM}(1,0.2)$ \\
\hline Orders from $(\mathrm{M})$ to $\mathrm{VE}$ & $\begin{array}{l}\text { Family1 - Randomly to VE1 and VE2 } \\
\text { Family2 - Randomly to VE2 and VE3 } \\
\text { Family3 - Randomly to VE3 and VE1 }\end{array}$ \\
\hline Information delay of back orders & $1 \mathrm{~min}$. \\
\hline \multicolumn{2}{|l|}{ Experimental Factors } \\
\hline Family-based dispatching rules (R) & FCFAM and MAS \\
\hline Forecast error (FE) & $\mathrm{FE}=1.5 * \mathrm{D} ; 3 * \mathrm{D} ; 5 * \mathrm{D}$ \\
\hline Review Period (RP) in min. & $\mathrm{RP}=6 ; 30 ; 60$ \\
\hline Information of back orders of echelons & $\begin{array}{l}\text { No information of Back orders (NOINF); } \\
\text { Manufacturer back orders information (MINF); } \\
\text { Manufacturer and Warehouse back orders information (MWINF) }\end{array}$ \\
\hline Inventory policy & $\begin{array}{l}\text { ROP = After Review Period, Order if inventory level touches ROP; } \\
\text { NOROP = Order after each review period, irrespective of ROP }\end{array}$ \\
\hline
\end{tabular}

Table 1: Overview of experimental factors and levels

\subsection{Fixed factors}

We consider three VEs capable of processing two pre-defined product families and having an unlimited buffer capacity. We assume there is no time delay between receiving orders from focal manufacturer and arrival of raw material into the defined queue for processing at VEs. The demand for each family is realized at retailers. Each retailer fulfills a single family demand, for instance, demand for family 1 is realized at Retailer 1, family 2 at Retailer 2 and so on. Specific 
attention is paid to the sensitivity of demand and is discussed in Section 5.1. The three VEs supply part families to a downstream focal manufacturer with the normally distributed supply lead times. The next echelon comprises of a warehouse catering the demand of three retailers to which the part families are sent, again with normally distributed lead times. We observe the minor set-up time for each job to be normally distributed over a small spread of 0.2. While switching from one family to another family in MAS dispatching rule case, we reiterate that the major set-up time is determined by considering the average of minor set-ups of available jobs of two families at VE.

We consider that an inter-holon information controller monitors the back order queues of each family at the downstream echelons after same instance of time (=1 min.). We assume the raw material equal to the back ordered demand is available for processing in the respective family queue without any time delay. From the parameter of information delay, one can infer that at different time instants the quantity of back orders may be different and hence it may affect the results. Therefore, the factor 'information delay of back order' is also considered for the sensitivity study in Section 5.1.

\subsection{Experimental factors}

In this study two well recognized FBD rules are analyzed for different operational configurations of inventory system adopted at downstream echelons from VEs. Downstream configurations are defined for a situation in which each SC holon determines its order size in a decentralized criterion. Decentralized setup implies the absence of any information sharing between echelon members; in this situation, each echelon member forecasts its demand for estimating safety stock and order-up-to levels on the size of the order placed to its immediate upstream echelon. Each echelon of the supply chain of the firm under study consider the forecasted demand higher than the realized demand due to the estimation error involved, i.e., demand $D_{\text {(Forecast) }}=\delta_{\varepsilon} * D_{\text {(Actual) }}$, where ' $\delta_{\varepsilon}$ ' is the magnitude of the assumed forecasting error (FE). This is consistent with Masuchun et al. (2004). Thus, we carried out the effect of forecasting error at three distinct levels: $1.5^{*} \mathrm{D}, 3^{*} \mathrm{D}$, and $5^{*} \mathrm{D}$ while comparing two FBD rules.

Another parameter that has great influence on the inventory control system and the SC system wide performance is the 'review period'. A plethora of literature is available dealing with inventory in which review period is focused as the factor affecting SC performance (Mohebbi, 2004; Li \& Chen, 2010; Samvedi \& Jain, 2011). On querying the Purchase Department Manager of the firm under study, it was found that reviewing the inventory was not very orderly. In the present paper, to analyze the effect of 'review period', we consider the inventory monitoring interval of 6, 30 and 60 time units. The decision for order replenishment is also greatly influenced by the instant when a definite quantity is available in inventory. The quantity at which the order is placed is referred to as reorder point. This factor is also dealt with extensively in literature for controlling the inventory system. Among various rules of inventory control, in the present paper, we analyze two well recognized rules concerning periodic review mode: (i) ROP the order is placed to the immediate upstream echelon as soon as the quantity left in storage is equal to or less than reorder quantity, (ii) NOROP - the order is placed after every review interval irrespective of quantity in storage. Previous research addresses the significance of different inventory control policies (Dev et al., 2012(b)).

As discussed in Section 3.1 and then in Section 4, in the present paper we consider an interholon information control setup in which back orders of downstream echelons are monitored. In this context at one extreme we consider that there is no back order information (NOINF), while 
at the other extreme of the continuum, we consider back orders of focal manufacturer as well as warehouse are monitored (MWINF). At intermediate (second) level of the factor we consider the back orders of manufacturer only are monitored (MINF).

\section{Simulation results}

In this section we analyze the outcomes of the study. Figure 6 shows the comparison of FCFAM and MAS dispatching rules when different forecasting error multiplier ' $\delta_{\varepsilon}$ ' is used by the partnering echelons, that is, the order size is determined in a decentralized fashion. The factor 'review period' is considered 6 time units and the order to the immediate upper echelon is triggered when the quantity in storage touches or is less than reorder point.

\section{Pl. Insert Figure 6 about here}

As seen in Figure 6, with the increasing value of forecasting error, the FBD rule, MAS outperforms the FCFAM rule, that is, the Average Flow Time in case of MAS is less than FCFAM when $\delta_{\varepsilon}$ equal to 5. For testing the statistical significance, Table 2 shows the analysis of variance (ANOVA) conducted for performance measures: Average Flow Time when the forecasting error is 1.5. The ANOVA is carried out at a confidence level of $99 \%(\alpha=0.01)$.

\begin{tabular}{cccccc}
\hline Source of variation & Sum squares & DF & Mean squares & F-EXP & F-CRIT \\
\hline FCFAM and MAS & 1.255 & 1 & 1.255 & 5009.933 & 98.503 \\
Error (W. Treatments) & 0.000495 & 2 & 0.000248 & & \\
Total & 1.255 & 3 & & & \\
\hline
\end{tabular}

Table 2: ANOVA of Average Flow Time for FCFAM and MAS rules at $\delta_{\varepsilon}=1.5$

As mentioned in Section 4.3, we have assumed forecast demand higher than the realized demand. As a result, the orders to the immediate upstream echelon would be larger in size with increasing values of forecasting error. It has similar notions of what we typically observe in demand amplification (bullwhip effect). Consequently, the production order size would proportionately be large at the manufacturing end. This results in higher work in process (WIP) inventory. From the result shown in Figure 6, we find that with the adoption of appropriate FBD rule, the average flow time is reduced. The time based measurement of WIP is the flow time. For a given throughput rate flow time is directly proportional to WIP (Little's law, 1961). From the above, therefore, we can say that WIP inventory can be reduced by adopting an appropriate FBD rule.

Alternatively, to get a better feel of it we carried out another simulation experiment in which 'Average queue time per job' at manufacturing end was computed. We specifically carried out this experiment for the MAS dispatching rule as we are more focused towards potentials of this FBD rule under different inventory variables. The 'Average queue time per job' for MAS dispatching rule for increasing values of forecasting error is shown in Figure 7. As seen in Figure 7, corresponding to least Average Flow Time (at $\delta_{\varepsilon}=5$ ), MAS shows minimum 'Average queue time per job'. Thus, the appropriate FBD rule at the manufacturing end contributes to mitigate 
the inventory levels in the total SC system that could be caused by demand amplification (bullwhip effect) due to forecasting. To this end, the present research provides a direction for the attenuation of demand amplification viewed from the FBD rules perspective. However, to address the issue of extent by which the effect of demand amplification or bullwhip effect can be mitigated by adopting a specific FBD rule could be the subject for future research.

\section{Pl. Insert Figure 7 about here}

We now report the results concerning re-order point. In this analysis, we carried out two experiments: ROP and NOROP at different values of review period, as mentioned in Section 4.3. Figure 8 (a) and (b) shows that FCFAM dispatching rule outperforms the MAS dispatching rule, irrespective of re-ordering policy (ROP or NOROP) considered in inventory system. However, in case of NOROP, the difference in value of Average Flow time between FCFAM and MAS is comparatively less. From this result, it is apparent to carry out an experiment with increasing values of review period at greater value of forecasting error $\left(\delta_{\varepsilon}=5\right)$. From Figure 8 (c), the correspondence of this result in Figure 6 is clear. The MAS dispatching rule is beneficial at larger values of forecasting error $\left(\delta_{\varepsilon}=5\right)$ irrespective of increase in review period values.

\section{Pl. Insert Figure 8 about here}

We now discuss the results of the experiments that involve back order information. Figure 9 shows that MAS dispatching rule significantly out performs FCFAM with higher information coordination among supply chain holons - there is availability of information of backorders of focal manufacturer and warehouse both (MWINF). Table 3 shows ANOVA conducted with the information coordination at level MWINF. The ANOVA is carried out at a confidence level of $99 \%(\alpha=0.01)$.

\begin{tabular}{cccccc}
\hline Source of variation & Sum squares & DF & Mean squares & F-EXP & F-CRIT \\
\hline FCFAM and MAS & 12.1 & 1 & 12.1 & 74564.62 & 98.503 \\
Error (W. Treatments) & 0.0003245 & 2 & 0.000162 & & \\
Total & 12.1 & 3 & & & \\
\hline
\end{tabular}

Table 3: ANOVA of Average Flow Time for FCFAM and MAS rules in the MWINF case

\section{Pl. Insert Figure 9 about here}

\subsection{Sensitivity analysis - Demand at retailers and information delay of back orders}

The study carried out in Section 5 call for two sensitivity issues: Demand at retailers' end and information delay of back orders. We specifically focus MAS dispatching rule for carrying out sensitivity study. As seen in the analysis of forecasting error factor, benefits are realized in case 
of MAS dispatching rule when the value of forecasting error is high $\left(\delta_{\varepsilon}=5\right)$. This result foresees an issue that if the order size from focal manufacturer is large, MAS dispatching rule over shadows the FCFAM rule. Therefore, we carried out an experiment in which demand at all the retailers was considered with time between arrivals as exponentially distributed (EXPO $(0.1))$. As anticipated, in contrast to result shown in Figure 6, we find that the MAS dispatching rule with Average Flow Time (=0.4298 min.) out performs FCFAM (=1.264 min.) at low values of forecasting error $\left(\delta_{\varepsilon}=1.5\right)$.

Similarly, we carried out an experiment to study the sensitivity of back order information delay on MAS and FCFAM. In this experiment we consider monitoring of back orders for increasing values of time delay. We find that the results were in harmony with the result shown in Figure 9; MAS dispatching rule out performed FCFAM significantly when there is availability of information of backorders of focal manufacturer and warehouse both (MWINF). However, we foresee a sensitivity issue pertaining to review period factor. Therefore, we studied the effect of increasing values of review period on back order information at level MINF and MWINF. Interestingly, at level MINF, FCFAM outperforms MAS at larger value of review period $(=60$ time units) as shown in Figure 10. The ANOVA result shown in table 4 validates the result. However, the results remain unperturbed with the increasing values of review period in case of back order information level MWINF - MAS dispatching rule remains favorable for increasing values of review period in consistent with the result shown in Figure 9.

\begin{tabular}{cccccc}
\hline Source of variation & Sum squares & DF & Mean squares & F-EXP & F-CRIT \\
\hline FCFAM and MAS & 3.831 & 1 & 3.831 & 90802.469 & 98.503 \\
Error (W. Treatments) & 0.0000843 & 2 & 0.0000422 & & \\
Total & 3.831 & 3 & & & \\
\hline
\end{tabular}

Table 4: ANOVA of Average Flow Time for FCFAM and MAS at level MINF with RP=60

\section{Pl. Insert Figure 10 about here}

\section{Discussion of results}

In this paper, we studied the use of two well-known family-based dispatching rules FCFAM and MAS under the premise of differing inventory policies adopted at various supply chain holons. In particular, we conceptualize various informational potentials at intra and inter-holon levels consistent with Holonic paradigm suggested by Koestler (1967). We now discuss the results obtained so as to underline some of the observations that respond to the objectives defined in Section 2 from the FBD rules perspective. The specific focus of study remains, in what situations MAS dispatching rule outperforms the conventional FCFAM rule. In view of this the potential findings of the present paper are:

- The shop load is realized from the order size that each immediate downstream SC holon sends to the upper holon. This provides a more realistic picture while selecting the FBD rule at the manufacturing end.

- MAS dispatching rule shows its potential at high values of shop load caused by larger order size. This is quite intuitive due to the value in the denominator of its relation: Average Flow Time. The threshold, at which the effect of denominator 
shows its potential for a specific FBD rule, greatly depends on the quantity ordered from the downstream echelon which in turn depends upon the operational parameters of the inventory system.

- Given the stochastic nature of various operational units involved in a SC network, simulation plays a more critical role in finding the optimal trade-off among the involved variables (inventory policies, demand patterns, etc.) with the FBD rules.

- Significant improvement of Average Flow Time is possible by strategically employing the suitable FBD rule at the manufacturing end under varying inventory control policies at downstream SC holons. This provides leverage to managers in case of due-date problem in mass customization.

- A considerable benefit is realized if larger numbers of SC holons involves in information sharing.

- Backorder information is greatly affected by the interval of monitoring the inventory level - the review period factor. This result underlines the fact that for the larger review periods, the back orders get depleted by the demand from downstream SC holon. Thus, the shop load decreases and thereby the benefit of the MAS dispatching rule diminish.

- If larger number of SC holons are involved in information sharing the effect of varying review period does not show its potential.

- We find that switching inventory monitoring policy from ROP to NOROP do not contribute to change in results. However, the sensitivity analysis experiment in which a surge in demand is assumed reflects the role of reorder point - due to larger values of demand, the value of the reorder point increases and thereby result large ordering size.

- The reduction in Average Flow Time by adopting MAS dispatching rule with increasing values of forecasting error indirectly shows a significant finding towards mitigation of effect of demand amplification (Bullwhip effect). The 'Average queue time per job' can be apportioned to the holding cost per job in storage, and thus cost saving by adopting a specific FBD rule. However, this issue needs due consideration for analyzing meticulously and can be regarded as option for future research.

\section{Conclusions}

We undertook a case study of a manufacturer involved in manufacturing of automobile parts and generator sets. We explore its outsourcing of components for turning operations to VEs under the purview of FBD rules. Some important conclusions from this case study were obtained which are the novel contributions of this paper from the managerial implication perspective. Therefore, it was suggested to corporate management of the firm to undertake the following:

(i) Contrary to the normal practice of adopting first come first serve rule for prioritizing, the jobs should be grouped into families and the prioritizing decision should be based upon the comparison of FBD rules.

(ii) Instead of realizing shop load locally, the FBD issue should be addressed as the result of inventory replenishment order requirements from the downstream echelons of SC network perspective. This certainly connotes to real life situation while studying the performance of the SC from system wide perspective.

(iii) Although, we had focused on a much smaller distribution network of the firm under study, however, the simulation approach for modeling supply chains provides advantages in development of the generic SC platform. This generic platform is instrumental to take 
on the complexities of multi-echelon interface interactions under inherent SC uncertainties (Wadhwa et al. 2008). Thus, the present SC model provides a generic construct and conceptual directionality to the issue addressed and can be used as a facsimile of any real life industrial SC setup under investigation as well. Thus, the simulation exercise of a wider distribution network of the firm can be undertaken as a future work.

(iv) Educate the benefits of information sharing in terms of improved Average Flow Time performance.

The other future research options includes: (i) the behavior of FBD rules under the premise of uncertainties within and at the interfaces of echelons (e.g., demand, lead times and its standard deviations), (ii) the behavior of FBD rules with the change in number of virtual enterprises and/or routing flexibility of families to VEs, (iii) the behavior of FBD rules for other SC structures, and (iv) the degree to which the appropriate FBD rules are beneficial in mitigation of unconstructive cost related to consequences of demand amplification i.e., Bullwhip effect.

\section{References}

1. Cachon, G.P., \& Fisher, M. (2000). Supply chain inventory management and the value of shared information. Management Science, 46(8), 1032-1048.

2. Chang, Y., \& Makatosoris, H. (2001). Supply chain modelling using simulation. International Journal of Simulation, 2(1), 24-30.

3. Chen, F. (1998). Echelon reorder points, installation reorder points, and the value of centralized demand information. Management Science, 44(2), 1221-1234.

4. Chen, Y.M., Liao, C.C., \& Prasad, B. (1998). A systematic application of virtual enterprising through knowledge management techniques. Journal of Concurrent Engineering Research and Application, 6(3), 225-244.

5. Christopher, M., \& Towill D. (2001). An integrated model for the design of agile supply chains. International journal of physical distribution logistic management, 31(4), 235246.

6. Christopher, M., \& Lee, H. (2004). Mitigating supply chain risk through improved confidence. International Journal of Physical Distribution and Logistics Management, 34(5), 388-396.

7. Dev, N.K., Caprihan, R., \& Swami, S. (2011). A case study of redesign of supply chain network of a manufacturing organization. Journal of Advances in Management Research, $8(2), 195-212$.

8. Dev, N.K., \& Shankar, R. (2012). Design of fractal information coordination system in a supply chain network. International Journal of Services and Operations Management, 12(1), 1-19. 
9. Dev, N.K., Caprihan, R., \& Swami, S. (2012). Strategic positioning of push-pull boundary within a supply chain: An ordering policy co-ordination perspective. Operations and Supply Chain Management, 5(1), 42-53.

10. Dominici, G. (2008). Holonic Production System to Obtain Flexibility for Customer Satisfaction. Journal of Service Science and Management, 1(3), 251-254.

11. Fernando, J.M.M., \& Sichman, J.S. (2010). Oil industry supply chain management as a holonic agent based distributed constraint optimization problem. In proceedings of $19^{\text {th }}$ European conference on Artificial intelligence, August 17, 2010, Lisbon, Portugal.

12. Fletcher, M., Garcia-Herreros, E., Christensen, J. H., Deen, S. M., \& Mittman, R. (2000). An open architecture for holonic cooperation and autonomy. In Proceedings of $11^{\text {th }}$ international Workshop on Database and Expert Systems Applications, pp. 224-230.

13. Frazier, G.V. (1996). An evaluation of group scheduling heuristics in a flow-line manufacturing cell. International Journal of Production Research, 34(4), 959-976.

14. Georges, M.R.R., Franco, G.N., \& Batocchio, A. (2009). Extending holonic manufacturing systems to achieve the virtual supply chain domain. Journal of Operations and Supply Chain Management, 2(2), 47-55.

15. Goletz, T., \& Ferreira, J.J.P. (2000). Enacting dynamic distribution networks - the DAMASCOS project. In: Camarinha-Matos, L.M., Afsarmanesh, H., Erbe, H. (Eds.), Advances in Networked Enterprises-Virtual Organizations, Balanced Automation and Systems Integration. Kluwer Academic Publishers, Dordrecht, 73-80.

16. Gupta, D. (1996). The (Q, R) inventory system with an unreliable supplier. INFORM 34(2), 59-76.

17. Hamedi, M., Esmaeilian, G.R., Ismail, N., \& Ariffin, M.K.A. (2012). Capability-based virtual cellular manufacturing systems formation in dual-resource constrained settings using Tabu search. Computers and Industrial Engineering, 62, 953-971.

18. Huang, B., Gou, H., Liu, W., Li, Y., \& Xie, M. (2002). A framework for virtual enterprise control with the holonic manufacturing paradigm. Computers in Industry, 49(3), 299-310.

19. Kannan, V. R., \& Ghosh, S. (1996). Cellular manufacturing using virtual cells. International journal of operations and production management, 16(5), 99-112.

20. Kara, S., \& Kayis, B. (2004). Manufacturing flexibility and variability: An overview. Journal of Manufacturing Technology Management, 115(6), 466-478.

21. Kelton, W.D., Sadowski, R.P., \& Swets, N.B. (2010). Simulation with Arena. $5^{\text {th }}$ ed. New York: McGraw-Hill.

22. Ko, H.H., Kim, J., Kim, S.S., \& Baek, J.G. (2010). Dispatching rule for non-identical parallel machines with sequence-dependent setups and quality restrictions. Computers and Industrial Engineering, 59, 448-457.

23. Koestler, A. (1967). The ghost in the machine. Arkana, London.

24. Kotak, D., Wu, S., Fleetwood, M., \& Tamoto, H. (2003). Agent-based holonic design and operation environment for distributed manufacturing. Computers in Industry, 52(2), 95108. 
25. Lau, R.S.M., \& Yam, R.C.M. (2005). A case study of product modularization on supply chain design and coordination in Hong Kong and China. Journal of manufacturing technology management, 16(4), 432-446.

26. Lewis, B. (2005). Inventory control with risk of major supply chain disruptions. Ph.D. thesis, Georgia Institute of Technology.

27. Li, X., \& Y. Chen. (2010). Impacts of supply disruptions and customer differentiation on a partial-backordering inventory system. Simulation Modelling Practice and Theory, 18(5), 547-557.

28. Little, J. (1961). A proof of the queuing formula $\mathrm{L}=\lambda * \mathrm{~W}$. Operations Research, 9, 383387.

29. Longo, F., Mirabelli, G., \& Papoff, E. (2005). Modelling analysis and simulation of a supply chain devoted to support pharmaceutical business retail. In the proceedings of $18^{\text {th }}$ International Conference on Production Research, Salerno, Italy.

30. Mahmoodi, F., Tierney, E.J., \& Mosier, C.T. (1992). Dynamic group scheduling heuristics in a flow-through cell environment. Decision Sciences, 23(1), 61-85.

31. Mahmoodi, F., \& Martin, G.E. (1997). A new shop-based and predictive scheduling heuristic for cellular manufacturing. International Journal of Production Research, 35(2), 313-326.

32. Masuchun, W., Davis, S., \& Patterson, J.W. (2004). Comparison of push and pull control strategies for supply network management in a make-to-stock environment. International Journal of Production Research, 42(20), 4401-4419.

33. Mohebbi, E. (2004). A replenishment model for the supply-uncertainty problem. International Journal of Production Economics, 87(1), 25-37.

34. Mosier, C.T., Elvers, D.A., \& Nelly, D. (1984). Analysis of group technology scheduling heuristics. International Journal of Production Research, 22(5), 857-875.

35. Narasimhan, R., \& Carter, J.R. (1998). Linking business unit and material sourcing strategies. Journal of Business Logistics, 19(2), 155-171.

36. Nomden, G., Van Der, D.J., \& Slomp, J. (2008). Family-based dispatching: anticipating future jobs. International journal of Production Research, 46(11), 73-97.

37. Olhager, J., \& Persson, F. (2006). Simulating production and inventory control system: A learning approach to operational excellence. Production Planning and Control, 17(2), 113-127.

38. Sahin, F., \& Robinson, E.P. (2002). Flow coordination and information sharing in supply chain: review, implications, and directions for future research. Decision Sciences, 33(4), 505-536.

39. Samvedi, A., \& Jain, V. (2011). Studying the impact of various inventory policies on a supply chain with intermittent supply disruptions. In the proceedings of the 2011 Winter Simulation Conference, Phoenix, AZ, 1641-1649.

40. Sensi, G. De, Longo, F., \& Mirabelli, G. (2008). Inventory policy analysis under demand patterns and lead times constraints in a real supply chain. International Journal of Production Research, 46(24), 6997-7016. 
41. Sheffi, Y., \& Rice, J. B. (2005). A supply chain view of the resilient enterprise. MIT Sloan Management Review, 47(1), 41-48.

42. Sihn, W. (1998). Manufacturing in networks-competitive advantages for virtual enterprise. In the proceedings of the International Conference of Manufacturing ValueChain, Troon, Scotland.

43. Suda, H. (1989). Future factory system formulated in Japan. Japanese Journal of Advanced Automation Technology, 1(1), 15-25.

44. Suwanruji, P., \& Enns, S.T. (2006). Evaluating the effects of capacity constraints and demand patterns on supply chain replenishment strategies. International Journal of Production Research, 44(21), 4607-4629.

45. Tang, C.S. (2006). Perspectives in supply chain risk management. International Journal of Production Economics, 103(2), 451-488.

46. Thomas, D.J., \& Griffin, P.M. (1996). Coordinated supply chain management. European Journal of Operations Research, 94(1), 1-15.

47. Van Brussel, H., Valckenaers, P., Bongaerts, L., \& Wyns, J. (1995). Architectural and systems design issues in holonic manufacturing systems. In Proceedings of the $3^{\text {rd }}$ IFAC/ IFIP/IFORS Workshop on Intelligent Manufacturing Systems IMS'95, 1-6.

48. Van der Zee, D.-J. (2013). Family based dispatching with batch availability. International Journal of Production Research, 51(12), 3643-3653.

49. Vernadat, F.B. (1997). Enterprise Modeling and Integration: Principles and Applications. London, U.K.: Chapman \& Hall.

50. Wadhwa, S., Mishra, M., Chan, F.T.S., \& Ducq, Y. (2008). Effects of information transparency and cooperation on supply chain performance: a simulation study. International Journal of Production Research, 48(1), 145-166.

51. Winkler, H. (2009). How to improve supply chain flexibility using strategic supply chain networks. Logistics Research, 1(1), 15-25. 


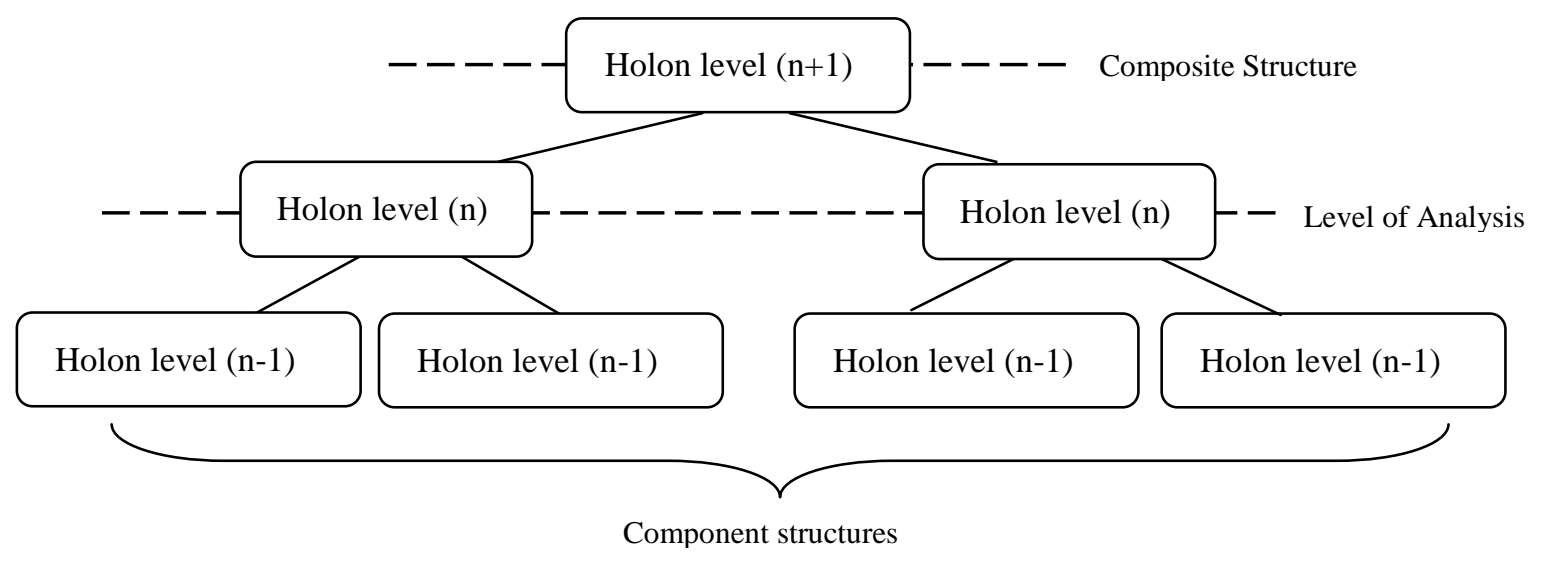

Figure 1: Holons and Holarchies (Source: Winkler, 2009)

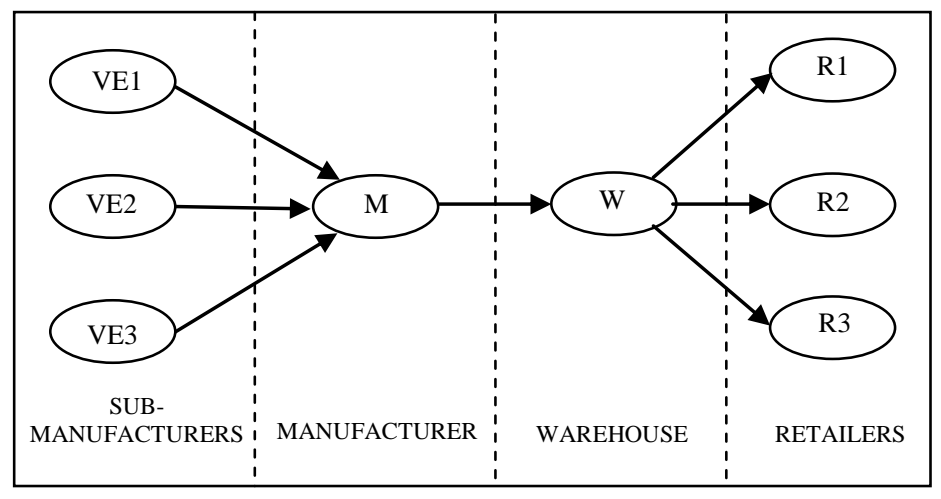

Figure 2: Supply chain network structure 


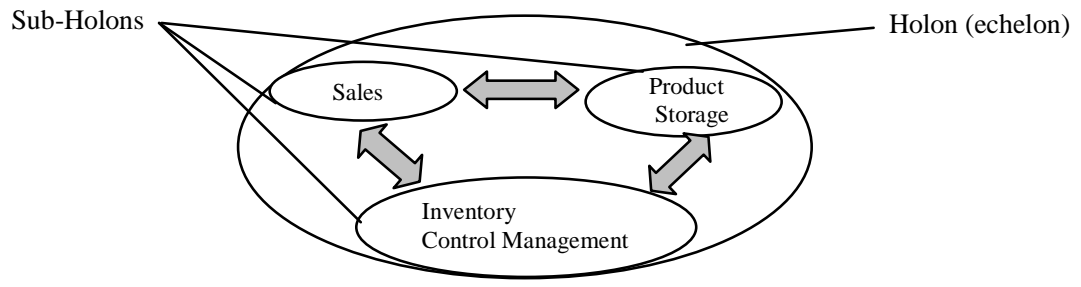

Figure 3: Operations performed within a holon (echelon)

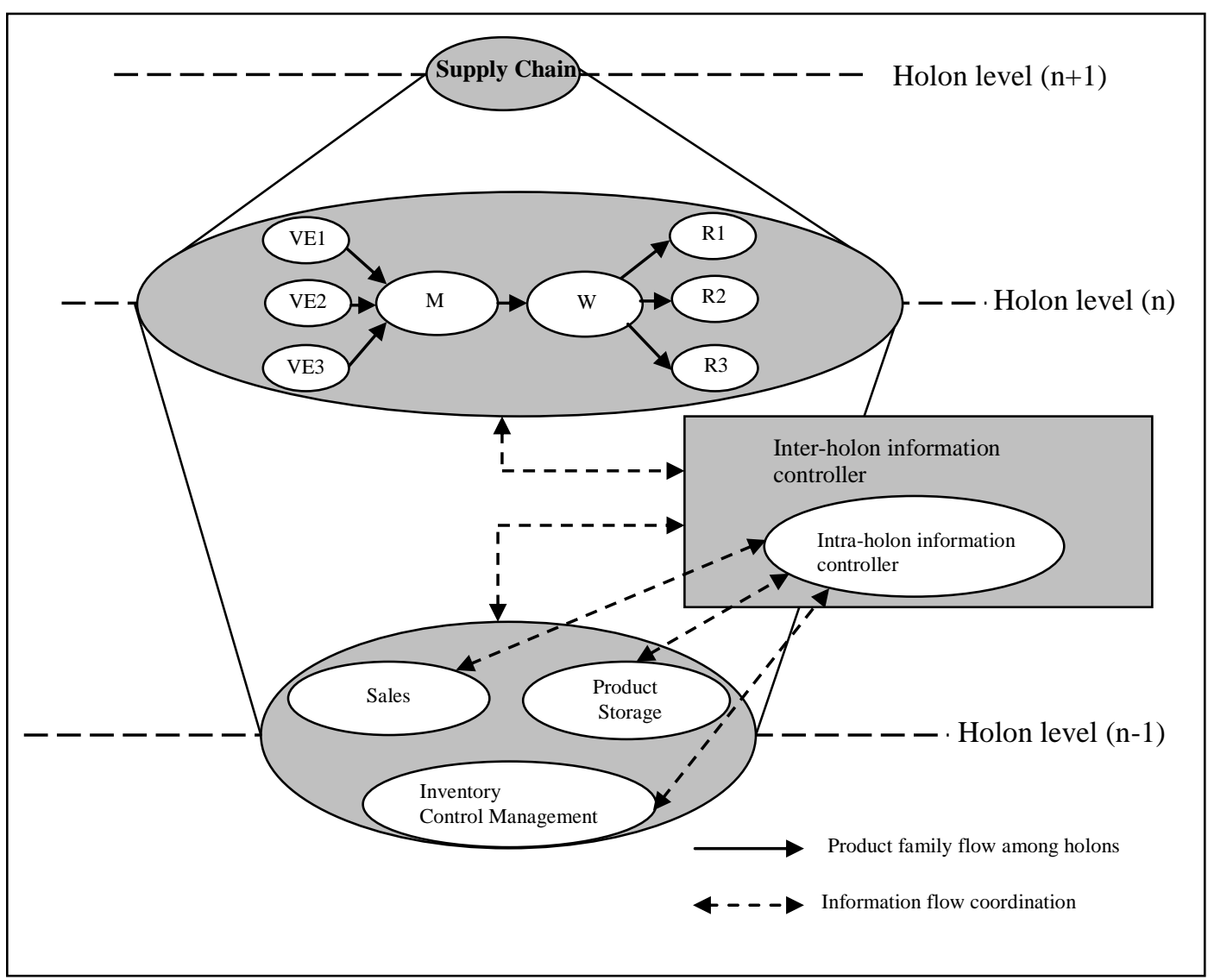

Figure 4: SC holarchy at different levels for simulation study 


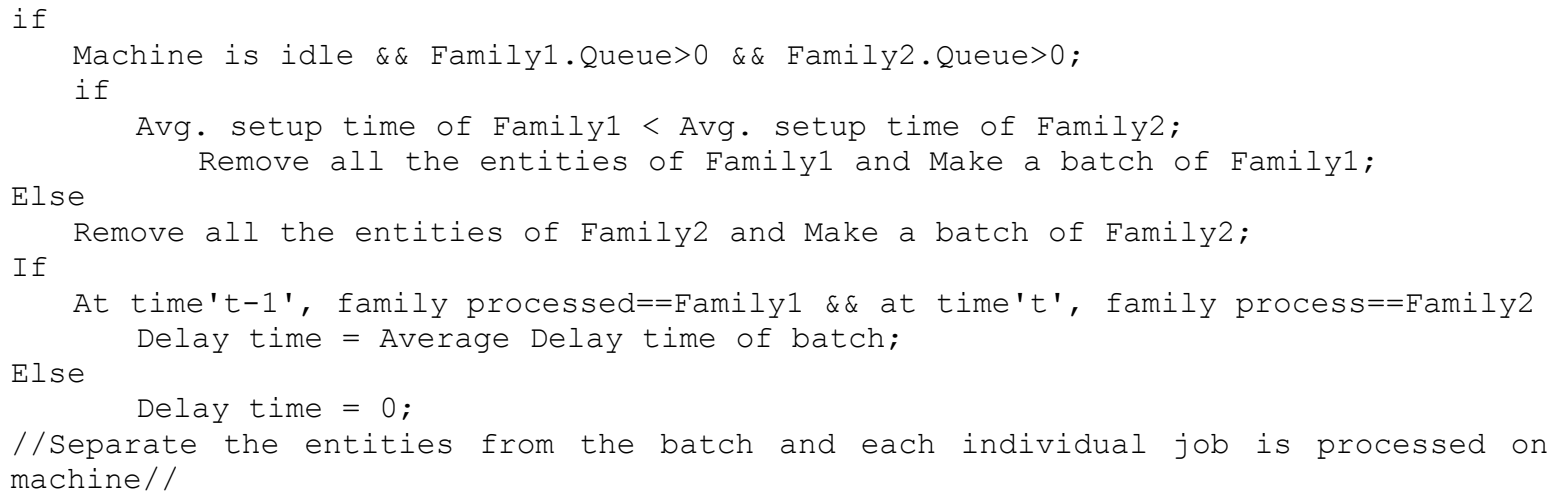

Figure 5: Algorithm of information holon model for MAS in simulation

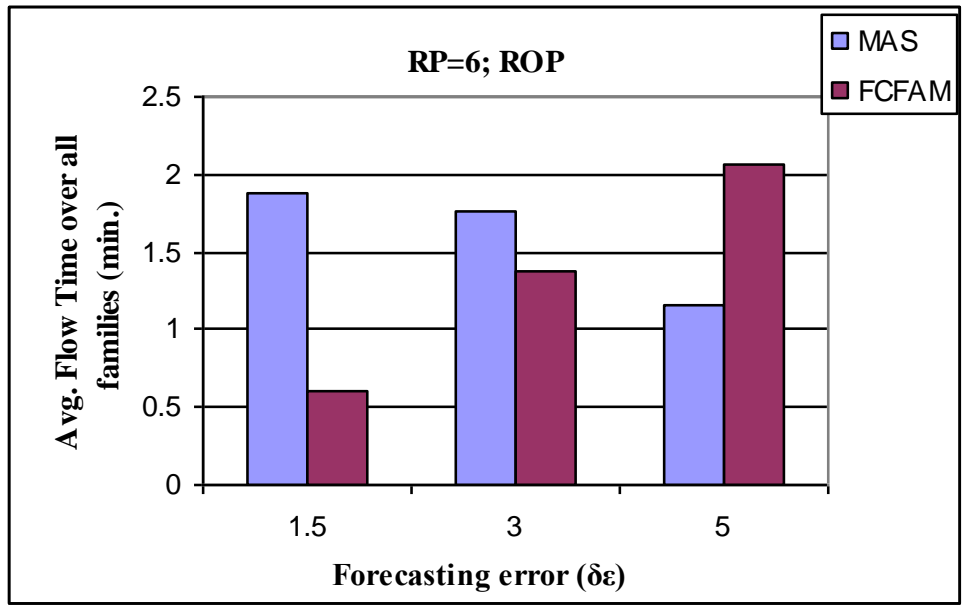

Figure 6: Comparison of FCFAM and MAS with increasing values of forecasting error ' $\delta_{\varepsilon}$ ' 


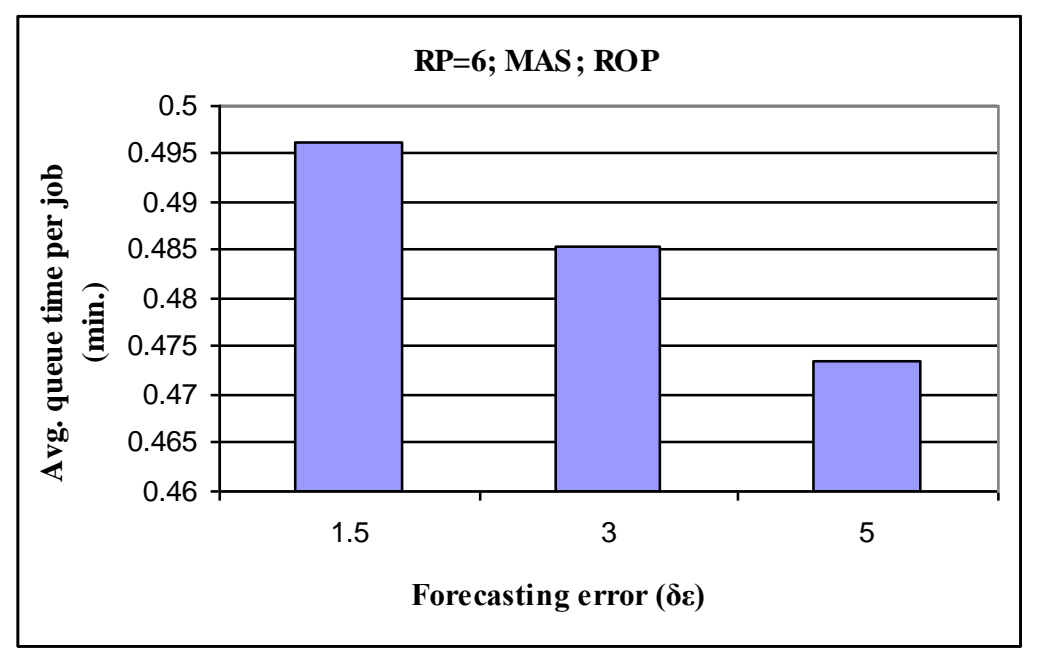

Figure 7: Average queue time per job for MAS dispatching rule

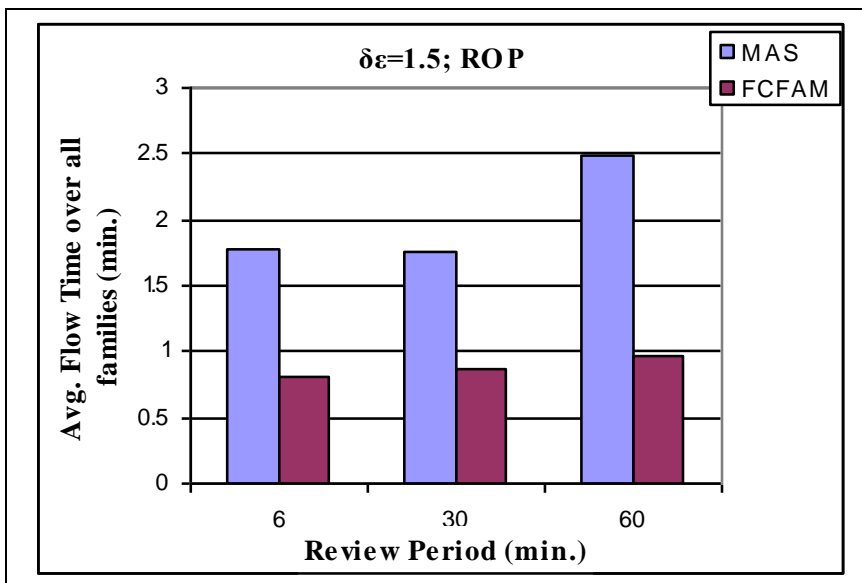

(a)

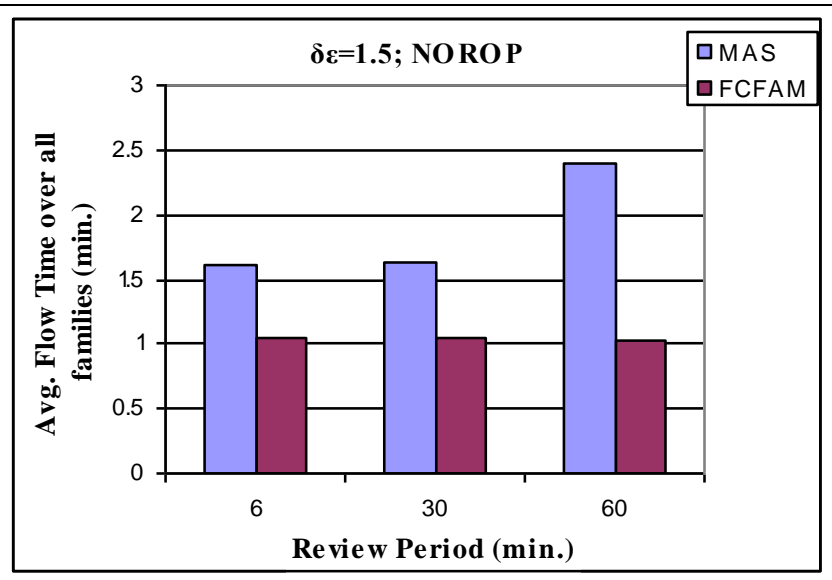

(b)

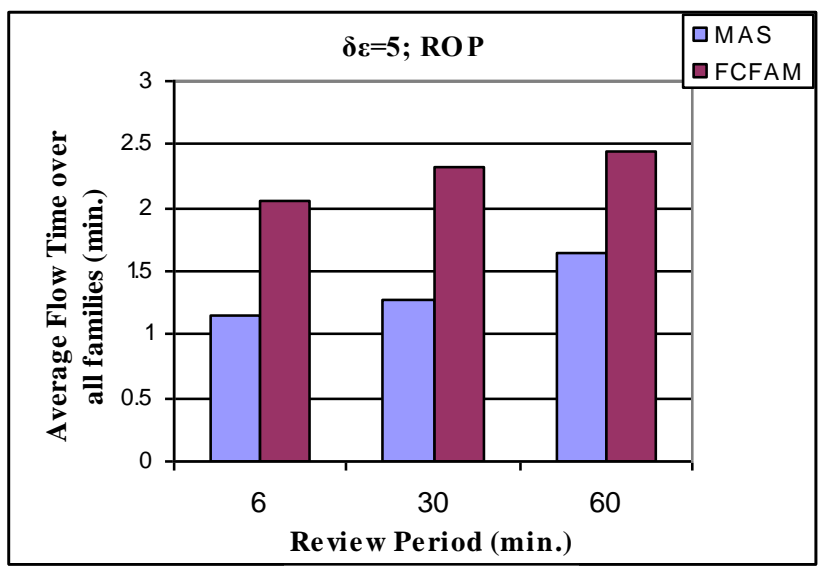

(c)

Figure 8: Average Flow Time at different review periods for (a) ROP, (b) NOROP case and (c) ROP with $\left(\delta_{\varepsilon}=5\right)$ 


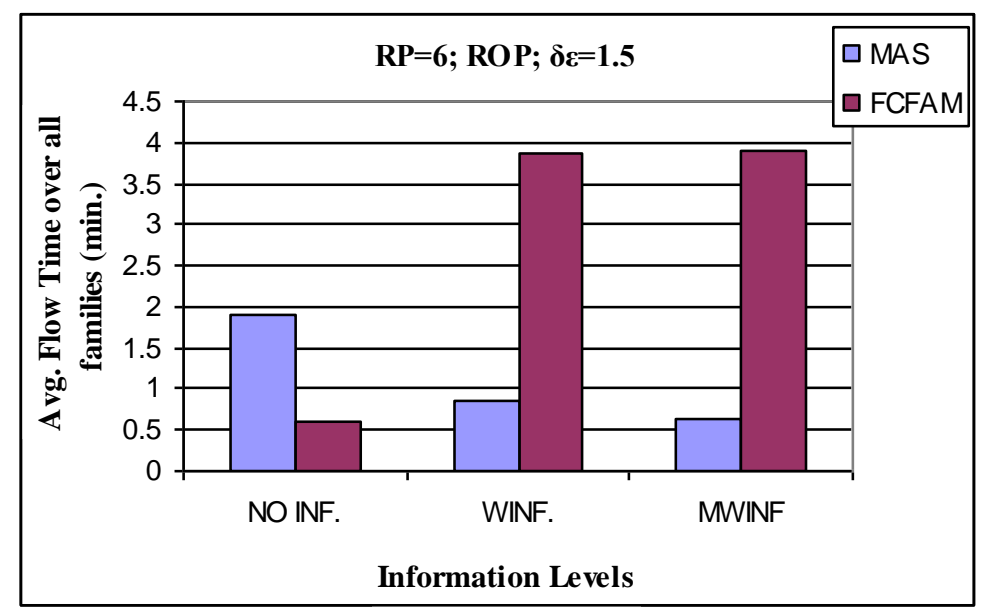

Figure 9: Average Flow Time at different levels of back order information

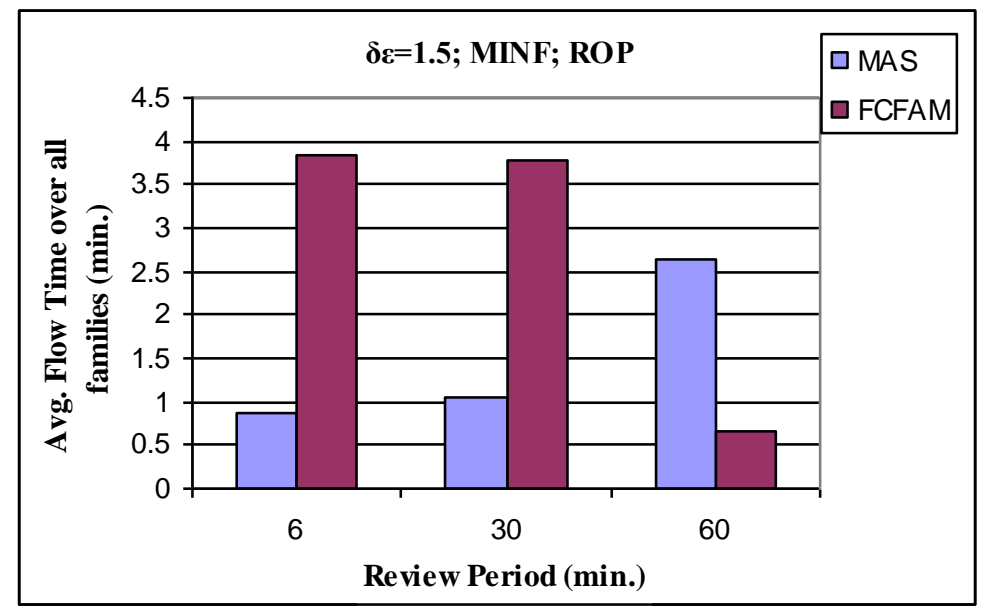

Figure 10: Average Flow Time at different review periods for the level MINF 


\title{
Holonic Supply Chain: A study from Family-Based Manufacturing Perspective
}

\begin{abstract}
In the contemporary business environment, to adhere to the need of the customers, caused the shift from mass production to mass-customization. This necessitates the supply chain (SC) to be effective flexible. The purpose of this paper is to seek flexibility through adoption of familybased dispatching rules under the influence of inventory system implemented at downstream echelons of an industrial supply chain network. We compared the family-based dispatching rules in existing literature under the purview of inventory system and information sharing within a supply chain network. The dispatching rules are compared for Average Flow Time performance, which is averaged over the three product families. The performance is measured using extensive discrete event simulation process. Given the inventory related operational factors at downstream echelons, the present paper highlights the importance of strategically adopting appropriate family-based dispatching rule at the manufacturing end. In the environment of mass customization, it becomes imperative to adopt the family-based dispatching rule from the system wide SC perspective. This warrants the application of intra as well as inter-echelon information coordination. The holonic paradigm emerges in this research stream, amidst the holistic approach and the vital systemic approach. The present research shows its novelty in triplet. Firstly, it provides leverage to manager to strategically adopting a dispatching rule from the inventory system perspective. Secondly, the findings provide direction for the attenuation of adverse impact accruing from demand amplification (Bullwhip effect) in the form of inventory levels by appropriately adopting family-based dispatching rule. Thirdly, the information environment is conceptualized under the paradigm of Koestler's holonic theory.
\end{abstract}

Key words: Supply Chain Coordination; Discrete Event Simulation; Average Flow Time; Family-Based Dispatching; Holonic Paradigm

\section{Introduction}

In the contemporary business environment, to adhere to the need of the customers, whose role has changed from a consumer to prosumer, that is, the saturation of markets with standardized products have pushed the customer towards the search for higher levels of differentiation and personalization of products. This behavior of customer has lead to an environment where most manufacturing companies shift from mass production to mass-customization (Dominici, 2008). Further, the manufacturing companies have realized that their performance with specific goals cannot be met adequately if operated in isolation. The spread of IT technology made it possible for the firms to seamlessly access the knowledge base, communicate, and negotiate with other echelon, which are autonomous with specific goals and resources. The ability to respond to customer orders in a timely fashion can provide a critical competitive advantage. These challenges warrant the needs for agility that are able to: a) suitably react to the market environment's instability; b) coordinate production system through the adoption of IT technologies; c) continuously examine the existing operational units for adaptive decisions so as to harness high level of performance measures. 
The above challenges of coordination can be viewed in the purview of theories on living organisms and social organizations, which, if applied to the business, present a representation of the firm as a living system. The holonic paradigm emerges in this research stream, amidst the holistic approach and the vital systemic approach. The holonic paradigm stems from the thoughts of (Koestler, 1967) who underlined how complex systems can originate only if they are composed of stable and autonomous sub-systems, which are able to survive turbulences and, at the same time, can cooperate forming a more complex system. Koestler suggests that analyzing both the biological and the physical universe shows that, it is necessary to take into account the relations between the whole and the part of the entity we observe. The term holon is a combination of the ancient Greek word 'holos' with the meaning of 'whole' and the suffix meaning 'entity' or part. The holon is, indeed, a whole which includes, simultaneously, the elements or the sub-parts which form it and give it structural and functional meaning. Holons act as intelligent, autonomous and cooperative entities working together inside hierarchies called 'holarchies'. A holarchy is a hierarchy of self-regulating holons working, in coordination with their environment, as autonomous wholes which are hierarchically superior to their own parts and, at the same time, are parts dependent with the control of superior levels. Figure 1 shows the general relationship between holon and holarchy. Holons of the same level process elements and information coming from lower level holons and they transfer the results to higher level ones for further processing. Processes of holons belonging to level ' $n$ ' hence originate from process of ' $n-1$ ' level subordinated holons and at the same time are the input for the processes of ' $n+1$ ' superior holons (Dominici, 2008).

In consistence to holonic theory, flexibility cannot be considered in only one single echelon of a supply chain. An improvement in the flexibility of an entire supply chain (SC) is necessary to harness high level of performance results (Christopher \& Towill, 2001). Flexibility must be the inherent property of the firm to be agile. To attain a high level of supply chain flexibility (SCF), a strategic supply chain network has to be used to build up specific flexibility potential. Winkler (2009) distinguished these potential as: i) structural, and ii) technological. Structural potential concerns designing the virtual organizations that enable a broad modularization in a supply chain. Thus customer orders can be routed through the supply chain network partners. This attribute of strategic supply chain network is called the 'liberty of orders' that ensures the selected partners can independently handle specific parts of customer's orders, in which they are fully responsible for order's fulfillment (Lau \& Yam, 2005).

\section{Pl. Insert Figure 1 about here}

Further, the increasing complexity of intelligent manufacturing systems has stimulated development of an emerging technology. This evolving technology paradigm is called Holonic Manufacturing Systems (HMS). The rational for needing HMS technology is that it represents a novel paradigm for addressing some of the most critical problems encountered as manufacturing businesses. These include (i) supporting product variety (mass customization) within a single shop floor, (ii) short 'order-to-delivery' times, and (iii) integrating supply chains to hold minimal reserve stocks.

Within the purview of above potentials, researchers remain incisive for functionalities beyond the boundaries of manufacturing; it could obtain better competitive edges if it were, gathering external partners that do some tasks in better ways than it ordinarily does by itself. Hence, the virtual enterprises (VE) within a supply chain network, was a natural result of HMS 
(Georges et al., 2009). VE refers to a temporary alliance of enterprises that come together to share skills or core competencies and resources in order to better respond to business opportunities, and whose cooperation is supported by computer networks (Goletz \& Ferreira, 2000). Sihn (1998) states that a VE combines various companies while maintaining the greatest possible flexibility and business independence. Huang et al. (2002) have developed a holonic framework for virtual enterprises. The planning of VE activities was carried out by a set of holons while scheduling is executed autonomously by each partner enterprise.

Technological potential is concerned with information technologies. Information sharing among various echelons of a supply chain is an important prerequisite for the realization of its flexibility potentials. Information system supports the integration of partners and liberty of orders in the strategic supply chain network. The information system of a strategic supply chain network bears the characteristic to share information between all the partners of the value-added processes. With a high degree of versatility of the resources used, it is very useful to cooperate with some partners that hold needed resources in the strategic supply chain network (Kara \& Kayis, 2004). This leads to 'plug and produce' system for order processing, means that partners are connected swiftly through logistics intrinsically.

The present study is motivated by undertaking a case study of a manufacturing firm situated in Haryana, India. The manufacturing firm is engaged in production of oil pumps, clutches, and sprockets for various automobiles like motorcycles, scooters, three-wheelers, mopeds and stationary engines such as generator sets. The firm is extensively involved in outsourcing some of their machining of turned components viz', main jet, needle jet, air adjuster, emulsion tube, valve seat, and bush valve seat to three local manufacturers located at an arm's distance. These local manufacturers are connected logistically to the concerned company in a very swift manner. Typically, we can refer to these local manufacturers as VEs. Each of these VE is equipped with CNC Turning centers that are capable of machining any of the above mentioned components. It was observed that the machining of the components at these VEs was carried out solely on the first come first serve basis. This required a major set-up time for switching from one type of component to the other. Set-up time includes loading the raw material, arranging clamping fixtures, uploading the NC program, and placing the required tools into the tool carousel. We further observed that these components can certainly be grouped into families, according to their shape and sequence of operations required. Thus, we segregated the above components into three families.

Picking up on this lead, we associate the case study to the notions of virtual cell manufacturing (VCM) under the purview of structural and technological potentials discussed above. VCM starts from the idea that grouping efficiencies can be realized using family-oriented scheduling/dispatching rules (Kannan \& Ghosh, 1996). Rules for family-based dispatching (FBD) are made assuming a two-phase approach, in which the choice of a family precedes the choice of a specific job-from the set of jobs available for the family (Mosier et al. 1984). Essentially, alternative rules for family-based dispatching only differ with respect to family priority setting. These rules strive to improve lead time performance by reducing set-up time. This is realized by grouping products that share similar requirements with respect to system setup, i.e. families, for joint dispatching. The surrogate measure of lead time is the Flow Time performance. In literature, most of the definitions for family priority setting are driven by the experimental factors considered autonomously at the manufacturing end (Nomden et al., 2008). In such a case, the issue of FBD rules raises a question such as: 
- Has the strategic adoption of specific FBD rule been adequate for enhancing Flow time performance when manufacturing entity operates in isolation to system wide business organization?

From a managerial point of view, given the high degree of intrinsic structural and technological $\mathrm{SCF}$, to deal with the mass customization environment, it is important to understand the effect of FBD rules on Flow Time performance from the integrated SC system perspective.

In view of above, the present paper contributes to the knowledge of the benefit of familybased dispatching (FBD) rules from the total SC perspective. The FBD rules are analyzed addressing the issue of Average Flow Time performance in the presence of operational parameters, especially associated with inventory and information sharing systems adopted at various echelons (holons) of the supply chain network of the firm under study. The Average Flow Time performance is measured at the VEs by averaging over the entire product families. To keep the results tractable, we limit ourselves to two dispatching rules mentioned in the literature: First come family (FCFAM) and Minimum average set-up time (MAS), while the complexity is considered in inventory system and SC structure. FCFAM rule shows similarities with the well known first come first serve rule (FCFS). It prioritizes families by considering the earliest entry moment of the jobs available in the queue for a family. MAS relates to the priority decision based on family set-ups to the respective number of items in queue. In the anticipation of the benefit of dispatching rules towards the reduction of Average Flow Time, we carried out extensive simulation.

This paper is structured as follows. In Section 2 we survey the literature and outline our research contributions. Section 3 demonstrates the supply chain network description of the firm under study in terms of the decision making process at various echelons, and inventory control procedure. To realize the potential of alternate FBD rules in the purview of various inventory related operational settings at holarchy levels, we conducted extensive simulation. The simulation design for various factors is explained in Section 4. Simulation results and its discussion are discussed in Section 5 and 6 respectively. Finally, conclusions are summarized in Section 7.

\section{Literature review}

The literature contains a diverse range of interpretations of Koestler's concepts for manufacturing. The application of these ideas was first studied by Suda (1989), who discussed the dynamic organizational structure of a highly automated holonic manufacturing system. The Japanese initiative on Holonic Manufacturing involves a multi-national collaborative research activity under Intelligent Manufacturing Systems (IMS) programme. This collaborative effort also involves several Japanese companies, namely Hitachi Ltd., Toshiba Corp., Yaskawa Electric, Fanuc and Hitachi Seiko. The ultimate aim is to develop a solution for high variety and variable batch size manufacture through the development of architecture for highly decentralized manufacturing systems, built from a modular mix of autonomous, cooperative and intelligent elements (Van Brussel et al. 1995; Fletcher et al. 2000; Kotak et al. 2003). A framework for modeling virtual enterprises using the holonic approach is presented by Huang et al. (2002) wherein each VE holon has four corresponding sub-holons, planning, scheduling, task and resource holons. Resource holon further comprises factory, shop-floor, workstation and cell holons. Although there are many instances of the application of holonic manufacturing, this paper demonstrates the issue of application of holonic paradigm applied for modeling of supply chain network. The impetus for the development of modeling through holonic approach is due to 
the increasing need of system wide coordination in SC network as in the existing competitive market, there is no one single organization that could respond to the need of providing products and services independently. Thomas and Griffin (1996) and Narasimhan and Carter (1998) believe that efficient management and appropriate integration of an SC entails coordination of product and information among suppliers, manufacturer, and the customer. Chen et al. (1998) and Vernadat (1997) suggested solving these problems through the involvement of virtual enterprises that quickly provide the right information to the right place, at the right time, and with the right format. Fernando and Sichman (2010) developed a theoretical model that combines a constraint network approach and a holonic multi-agent approach to support coordination and management of a typical oil industry supply chain.

Mass customization and increasing competition force manufacturers in various industries towards higher level of responsiveness. Group technology provides one of the answers to meet these demands. The key idea underlying this concept is the exploitation of similarities in product and process design that result in the study of family-based dispatching rules for shop floor control (Mahmoodi et al. 1992; Frazier, 1996; Mahmoodi \& Martin, 1997). Kanan and Ghosh (1996) proposed two 'look-ahead' dispatching schemes called VCM3 and VCM5. Both rules start from the idea that the operator is informed about the set of families which, next to having one or more jobs in the queue, also have jobs being processed in a preceding machine. Nomden et al. (2008) studied family-based dispatching rules taking information technology into account. While prioritizing they consider the queue length of the family, which is yet to arrive according to information provided to the downstream machine operator. Hamedi et al. (2012) suggested capability-based Virtual Cellular Manufacturing System. They developed Goal Programming model in which parts, machines, and workers are grouped and showed the efficient utilization performance. Ko et al. (2010) suggested the job dispatching rule based on product quality index and simultaneously focused on meeting due dates. Van der Zee (2013) considered FBD based on batch availability in shop i.e., the jobs of same batch become available for processing and leave the machine together. The author compared the proposed rule with existing exhaustive and nonexhaustive rules in literature. The outcomes of the simulation study found that proposed extended rule has improved system performance in terms of Flow time.

However, most of the family-based studies are driven by the assumptions confined to shop floor or by the manufacturing oriented parameters. In contrary to it, the contemporary business environment does not allow any entity of the value chain to operate in isolation for enhancing the system wide performance.

The potential of supply chain responsiveness towards mass customization in order to minimize the Average Flow Time largely depends on the agility or the flexibility of the supply chain. Managing agility in the supply chain has never been as challenging as it is today. Supply chain risks are inherited in different kinds like natural disaster, terrorist attack, labor strike and accidents. These can all be the causes for supply chain disruption and delay (Christopher \& Lee, 2004; Tang, 2006). Delay does not only halt the supply chain operations, but without preparation and precaution, it takes time for the affected system to recover (Sheffi \& Rice, 2005). Inventory management is an effective way of dealing with such disruption situations. A plethora of literature is available dealing with inventory during supply disruptions (Gupta, 1996; Lewis, 2005). However, study of inventory systems in real stochastic supply chains is one of the major concerns in today's supply chain management. As soon as the number of parameters affecting supply chain performance becomes high and the objective becomes the whole supply chain analysis, simulation plays a more critical role in finding the optimal trade-off among the 
involved variables (inventory policies, lead times, demand patterns, customers' satisfaction) as reported in Chang and Makatosoris (2001). To this end the Modelling and Simulation-based approach is jointly used with statistical techniques such as Design of Experiment and Analysis of Variance (Longo et al., 2005; Suwanruji \& Enns, 2006). The state-of-the-art overview highlights that Modelling and Simulation in combination with statistic techniques is usually used for analyzing supply chain scenarios (Sensi et al., 2008).

Further, it is well-acknowledged in the supply chain literature that information sharing and physical flow coordination can lead to enhanced supply chain performance (Chen, 1998; Cachon $\&$ Fisher, 2000). Sahin \& Robinson (2002) reported comprehensive surveys of the supply chain information sharing and coordination literature. Wadhwa et al. (2008) highlighted the observations regarding cooperation and information transparency in the supply chain. The authors mentioned that even under the conditions of stock-out inventory the customer requires a certain degree of reliability from the enterprise towards fulfillment of stock-out demand. Such is a typical case of a concern for the agile enterprise. These enterprises, under such stock-out condition eventually needs to fulfil the demand through cooperative mechanism. Dev et al. (2011, 2012(a)) suggested sharing of demand information across various echelons of supply chain network for the performance improvement over the entire supply chain.

In view of above, we attempt to fill a gap by associating the real industrial case and realizing various issues from the following viewpoint.

(i) The potential of flexibility of manufacturing system is analyzed through FBD rules from the total supply chain perspective.

(ii) The complexity of manufacturing system is viewed from the application of Koestler's holonic concept.

(iii) While comparing FBD rules, the shop floor load is realized through the stochastic behavior of supply chain disruptions affecting inventory system of downstream echelons.

(iv) The impact of information coordination of FBD rules are investigated from a supply chain perspective.

Therefore, with the above necessary analysis, for which there is little to no literature exist, we foresee that the present paper provides a sound and an insightful basis for exploring the relevance of assumed FBD rules from the view point of total supply chain. The SC network of the firm under study is analyzed for the Average Flow Time performance over the assumed number of product families under the purview of inventory system and informational coordination.

\section{Supply chain network description of the firm}

Although the manufacturing firm was engaged in the production and distribution of several engineering components for the automobile industry, we specifically carried out the study of the supply chain of the components mentioned in Section 1 so as to keep our motive of study focused to analyze FBD rules at VEs (the local manufacturers). The firm supplies its manufactured products to reputed original equipment manufacturers (OEMs) that cover a large sector of automobile industry in India. They also supply the components to the open market through product warehouse and retailers. The supply to the OEMs is well established in terms of supply volumes and lead time commitments on account of contractual agreements. However, distribution on the open market is typically subject to the uncertainties and was therefore chosen as the focus for this case study. It was decided to focus on the distribution network within the 
given city for the sake of model tractability. This does not sacrifice our main focus of study to analyze the performance of alternative FBD rules at VEs from total supply chain perspective. The focal manufacturing firm (M) supplies the components to their warehouse (W) which caters the demand of three retailers (R1, R2 and R3) as shown in Figure 2. The performance is measured at three VEs associated with the focal firm under study with a high degree of intrinsic logistics capabilities. In our study system of supply chain network, we compared two FBD rules, FCFAM and MAS for the operational performance, Average Flow Time. Further, each of the three distinct retailers experience same demand patterns of three product families, each of which are exponentially distributed with same mean value. This positively appends to the analysis as it would illustrate the impact of inventory related parameters on two different FBD rules. We now discuss various structural and informational systems at various echelons.

\section{Pl. Insert Figure 2 about here}

\subsection{A framework for decision making at echelons}

As the performance measure, Average Flow Time over the entire families is measured at VEs for two different FBD rules. Therefore, it is expedient to discuss first the framework for FBD rules at VEs. We assume that the focal manufacturer sends its orders to VEs (sub-manufacturers) according to predefined product family. We further assume a centrally operated controller, viewed as a holon that manages the order dispatching to VEs. Based upon the ordering policy adopted by the focal manufacturer, each of the three product families are randomly ordered for any of the two pre-defined VEs for its processing. For an instant, jobs of family 1 are processed at VE1 \& VE2, family 2 is processed at VE2 \& VE3, and VE3 \& VE1 are pre-selected for processing family 3 . This means, each VE is assumed to be capable of processing two families of products. We distinguish the framework between performance criterion, information criterion and decision options.

(i) Performance criterion - We consider the minimization of Average Flow Time over all the three families $(M F T)$ in the finite simulation run. Average Flow Time per job is defined as:

$$
M F T=\frac{\sum_{j \in J} \sum_{i=1,2, \ldots} f t_{i, j}}{N} \text { with } f t_{i, j}=w_{i, j}+p_{i, j}
$$

where job ' $i$ ' belonging to family ' $j$ ' $\left(f t_{i, j}\right)$ we distinguish between waiting time $\left(w_{i, j}\right)$ and job processing time $\left(p_{i, j}\right)$.

(ii) Information Criterion - We consider the different perspectives of information:

- Local data, like queue lengths per family, family set-up times and job processing times.

- Back order information, that is, we consider an information aspect that provides a high degree of flexibility in the analysis of Average Flow Time in case of family dispatching criteria. We propose a holonic agent that monitors the back orders at downstream echelons (focal manufacturer and warehouse). While comparing the assumed FBD rules for prioritizing the processing, the quantity of back orders belonging to the same family at the downstream echelons is taken into account. We assume an information delay in acquiring the quantity of back orders and consider it as an experimental factor. This kind of informational aspect supports the indications of high degree of flexibility proposed by Wadhwa et al. (2008) in which the authors mentioned that reliability towards fulfillment of stock-out demand can be enhanced through coordination.

(iii) Decision Options - Essentially a dispatcher have a few decision options available for triggering the family batches for the processing on machine: 
- Switch the machine set-up to meet the requirements of another family, according to the availability of machine and comparing two families at a VE for a minimum average set-up time in case of the MAS prioritizing model. Switching to different family constitute a delay time due to a major set-up time $s_{j 0, j}$. The length of the major set-up time is determined by averaging over the minor setups related to each job of the family in queue constituting a batch. If the major set-up time for the current set-up - for family $j_{0}$ - and the required set-up for family $j$, then apparently, $s_{j 0, j}=0$ for $j=j_{0}$. Products related minor set-ups are assumed to be normally distributed.

Let us now discuss the information criterion and decision options at downstream echelons; focal manufacturer, warehouse and retailers which are typically maintained and controlling the inventories of product families that are routed through the supply chain. We reiterate that in the present paper various inventory variables are the experimental factors, the impact of which is analyzed for Average Flow Time performance under the two FBD rules: FCFAM and MAS. We would like to mention here that the focal manufacturing organization under study is not equipped with any informational capability (e.g. EDI) setup of effecting seamless operational data exchange throughout the network. Basically, their ordering operations at each echelon entail three distinct sub-operations comprising of (i) Sales, (ii) Product storage; and (iii) Inventory Control Management. In the present paper the proposed setup view these distinct operations as sub-holons of a larger holon (echelon) having informational coordination. These sub-holons interact in real-time for processing of orders to be placed in the immediately preceding echelon member. Under information criterion, Figure 3 schematically shows the various operations performed by each downstream echelon while effecting ordering decisions in the supply chain network structure.

\section{Pl. Insert Figure 3 about here}

Informational and decision operations at various sub-holons include:

Sales sub-holon

- Receiving of orders from downstream echelon (customers in case of Retailers).

- Product disposal information to storage on getting inquiry about the availability of products.

- Orders to upstream echelon for inventory replenishment.

Product Storage sub-holon

- Disposal of products to the downstream echelon on receipt of orders from sales (to the customers in case of Retailers).

- Providing information to sales and the inventory controller about the current inventory levels.

Inventory control management sub-holon

- Computes the orders according to the inventory control system under experimental design. The order placed is based upon:

- The information from sales about the orders in-process; and

- The information from storage about the number of products in storage inventory.

- Sends information to sales for ordering to upstream echelon. 


\subsection{Inventory control procedure}

To ensure sufficient product inventory at the individual echelon stock points, each distinct echelon member of the firm under study adopts a conventional $(s, S)$ inventory control procedure (also called Min-Max Inventory Control Policy in the literature) operating in a periodic review mode. Here, 's' is the re-order point, while the ' $S$ ' is the order-up-to level (Olhager \& Persson, 2006). After receipt of a demand order, each retailer checks his product storage inventory, and if there is adequate inventory in store, demand is fulfilled completely. Else, the demand ordered is partially fulfilled from the inventory in stock, and the remaining amount is backordered. The backordered quantity is then replenished in a first-in, first-out (FIFO) manner. In the present study, we consider the back orders under the purview of informational coordination for the FBD batch operations. While at one extreme of coordination aspect we considered information about back orders, at the other end of the continuum of information coordination we consider a situation in which each echelon forecasts its demand (the practice being adopted by the supply chain under study). The forecast demand is assumed higher than the realized demand due to the

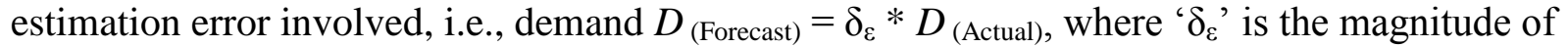
the assumed forecasting error (Masuchun et al., 2004). We also paid attention to its sensitivity towards the Average Flow time while comparing FCFAM and MAS.

\section{Design of simulation study}

A simulation study was designed to compare the strategic adoption of alternative FBD rules: FCFAM and MAS. In this section we discuss the experimental design by describing alternative configuration of VEs and inventory control system at downstream echelons: focal manufacturer, warehouse and retailers. As discussed in Section 3.1 and 3.2 about various informational and decision criteria at VEs and downstream echelons, the SC system in the present paper can be viewed from the holonic paradigm perspective in consistent to Winkler (2009) shown in Figure 4. Various echelons of assumed supply chain network at level (n) acts as the holons operating autonomously in managing their operational units, i.e. sales, product storage and inventory control management systems at level (n-1). These autonomous holons are under the holarchy of the supply chain of a total business system at the level $(n+1)$. Further, the information was realized at intra-holon level wherein various operational units share the information discussed in Section 3.1. In case of Inter-holon information controller, we reiterate our assumption that an information controlling holon monitors the back orders of downstream echelons (focal manufacturer and warehouse) and sends orders to corresponding VE associated with family processing. At each VE, in case of MAS dispatching rule, the dispatching causes once the jobs are available in two pre-specified family queues. The algorithm used in the simulation is shown in Figure 5.

\section{Pl. Insert Figure 4 about here}

\section{Pl. Insert Figure 5 about here}

\subsection{Experimental design}

A simulation model of the four-echelon supply chain network structure was developed in the Arena ${ }^{\circledR}$ simulation language (Kelton et al., 2010). The External Visual C++ code was linked into the Arena models to capture the inventory control logic utilized in the simulation model. Also, 
since simulation in Arena ${ }^{\circledR}$ involve samples from probability distributions (e.g., for customer demand, lead times and their standard deviations, etc.), it is recommended that a requisite number of replications of a sufficiently long duration (in order to eliminate the initial transient bias) be carried out in order to justify the normality assumption required for the statistical interpretation of simulation results. In our experiments, therefore, the simulation models were run for 10,000 simulation minutes (approx. seven days) each with 10 replications which was found adequate for analysis purposes. The performance measure of interest was Average Flow Time averaged over assumed three product families.

To study the impact of the assumed factors within the supply chain network structure, as a starting point for discussing the experimental design we adopt table 1. It specifies fixed and experimental factors.

\begin{tabular}{|c|c|}
\hline \multicolumn{2}{|l|}{ Fixed Factors } \\
\hline No. of families & 03 \\
\hline Holarchy levels (No. of Echelons) - 04 & $\begin{array}{l}\text { 3-Retailers; } \\
\text { 1-Warehouse; } \\
\text { 1-Focal Manufacturer; } \\
\text { 3-VEs }\end{array}$ \\
\hline Demand at 3-Retailers (D) & Time between Arrival $=\operatorname{EXPO}(0.5)$ \\
\hline Minor Set-up time distribution & $\operatorname{NORM}(5,0.2)$ \\
\hline Processing time distribution & $\operatorname{NORM}(1,0.2)$ \\
\hline Orders from $(\mathrm{M})$ to $\mathrm{VE}$ & $\begin{array}{l}\text { Family1 - Randomly to VE1 and VE2 } \\
\text { Family2 - Randomly to VE2 and VE3 } \\
\text { Family3 - Randomly to VE3 and VE1 }\end{array}$ \\
\hline Information delay of back orders & $1 \mathrm{~min}$. \\
\hline \multicolumn{2}{|l|}{ Experimental Factors } \\
\hline Family-based dispatching rules (R) & FCFAM and MAS \\
\hline Forecast error (FE) & $\mathrm{FE}=1.5 * \mathrm{D} ; 3 * \mathrm{D} ; 5 * \mathrm{D}$ \\
\hline Review Period (RP) in min. & $\mathrm{RP}=6 ; 30 ; 60$ \\
\hline Information of back orders of echelons & $\begin{array}{l}\text { No information of Back orders (NOINF); } \\
\text { Manufacturer back orders information (MINF); } \\
\text { Manufacturer and Warehouse back orders information (MWINF) }\end{array}$ \\
\hline Inventory policy & $\begin{array}{l}\text { ROP = After Review Period, Order if inventory level touches ROP; } \\
\text { NOROP = Order after each review period, irrespective of ROP }\end{array}$ \\
\hline
\end{tabular}

Table 1: Overview of experimental factors and levels

\subsection{Fixed factors}

We consider three VEs capable of processing two pre-defined product families and having an unlimited buffer capacity. We assume there is no time delay between receiving orders from focal manufacturer and arrival of raw material into the defined queue for processing at VEs. The demand for each family is realized at retailers. Each retailer fulfills a single family demand, for instance, demand for family 1 is realized at Retailer 1, family 2 at Retailer 2 and so on. Specific 
attention is paid to the sensitivity of demand and is discussed in Section 5.1. The three VEs supply part families to a downstream focal manufacturer with the normally distributed supply lead times. The next echelon comprises of a warehouse catering the demand of three retailers to which the part families are sent, again with normally distributed lead times. We observe the minor set-up time for each job to be normally distributed over a small spread of 0.2. While switching from one family to another family in MAS dispatching rule case, we reiterate that the major set-up time is determined by considering the average of minor set-ups of available jobs of two families at VE.

We consider that an inter-holon information controller monitors the back order queues of each family at the downstream echelons after same instance of time (=1 min.). We assume the raw material equal to the back ordered demand is available for processing in the respective family queue without any time delay. From the parameter of information delay, one can infer that at different time instants the quantity of back orders may be different and hence it may affect the results. Therefore, the factor 'information delay of back order' is also considered for the sensitivity study in Section 5.1.

\subsection{Experimental factors}

In this study two well recognized FBD rules are analyzed for different operational configurations of inventory system adopted at downstream echelons from VEs. Downstream configurations are defined for a situation in which each SC holon determines its order size in a decentralized criterion. Decentralized setup implies the absence of any information sharing between echelon members; in this situation, each echelon member forecasts its demand for estimating safety stock and order-up-to levels on the size of the order placed to its immediate upstream echelon. Each echelon of the supply chain of the firm under study consider the forecasted demand higher than the realized demand due to the estimation error involved, i.e., demand $D_{\text {(Forecast) }}=\delta_{\varepsilon} * D_{\text {(Actual) }}$, where ' $\delta_{\varepsilon}$ ' is the magnitude of the assumed forecasting error (FE). This is consistent with Masuchun et al. (2004). Thus, we carried out the effect of forecasting error at three distinct levels: $1.5^{*} \mathrm{D}, 3^{*} \mathrm{D}$, and $5^{*} \mathrm{D}$ while comparing two FBD rules.

Another parameter that has great influence on the inventory control system and the SC system wide performance is the 'review period'. A plethora of literature is available dealing with inventory in which review period is focused as the factor affecting SC performance (Mohebbi, 2004; Li \& Chen, 2010; Samvedi \& Jain, 2011). On querying the Purchase Department Manager of the firm under study, it was found that reviewing the inventory was not very orderly. In the present paper, to analyze the effect of 'review period', we consider the inventory monitoring interval of 6, 30 and 60 time units. The decision for order replenishment is also greatly influenced by the instant when a definite quantity is available in inventory. The quantity at which the order is placed is referred to as reorder point. This factor is also dealt with extensively in literature for controlling the inventory system. Among various rules of inventory control, in the present paper, we analyze two well recognized rules concerning periodic review mode: (i) ROP the order is placed to the immediate upstream echelon as soon as the quantity left in storage is equal to or less than reorder quantity, (ii) NOROP - the order is placed after every review interval irrespective of quantity in storage. Previous research addresses the significance of different inventory control policies (Dev et al., 2012(b)).

As discussed in Section 3.1 and then in Section 4, in the present paper we consider an interholon information control setup in which back orders of downstream echelons are monitored. In this context at one extreme we consider that there is no back order information (NOINF), while 
at the other extreme of the continuum, we consider back orders of focal manufacturer as well as warehouse are monitored (MWINF). At intermediate (second) level of the factor we consider the back orders of manufacturer only are monitored (MINF).

\section{Simulation results}

In this section we analyze the outcomes of the study. Figure 6 shows the comparison of FCFAM and MAS dispatching rules when different forecasting error multiplier ' $\delta_{\varepsilon}$ ' is used by the partnering echelons, that is, the order size is determined in a decentralized fashion. The factor 'review period' is considered 6 time units and the order to the immediate upper echelon is triggered when the quantity in storage touches or is less than reorder point.

\section{Pl. Insert Figure 6 about here}

As seen in Figure 6, with the increasing value of forecasting error, the FBD rule, MAS outperforms the FCFAM rule, that is, the Average Flow Time in case of MAS is less than FCFAM when $\delta_{\varepsilon}$ equal to 5. For testing the statistical significance, Table 2 shows the analysis of variance (ANOVA) conducted for performance measures: Average Flow Time when the forecasting error is 1.5. The ANOVA is carried out at a confidence level of $99 \%(\alpha=0.01)$.

\begin{tabular}{cccccc}
\hline Source of variation & Sum squares & DF & Mean squares & F-EXP & F-CRIT \\
\hline FCFAM and MAS & 1.255 & 1 & 1.255 & 5009.933 & 98.503 \\
Error (W. Treatments) & 0.000495 & 2 & 0.000248 & & \\
Total & 1.255 & 3 & & & \\
\hline
\end{tabular}

Table 2: ANOVA of Average Flow Time for FCFAM and MAS rules at $\delta_{\varepsilon}=1.5$

As mentioned in Section 4.3, we have assumed forecast demand higher than the realized demand. As a result, the orders to the immediate upstream echelon would be larger in size with increasing values of forecasting error. It has similar notions of what we typically observe in demand amplification (bullwhip effect). Consequently, the production order size would proportionately be large at the manufacturing end. This results in higher work in process (WIP) inventory. From the result shown in Figure 6, we find that with the adoption of appropriate FBD rule, the average flow time is reduced. The time based measurement of WIP is the flow time. For a given throughput rate flow time is directly proportional to WIP (Little's law, 1961). From the above, therefore, we can say that WIP inventory can be reduced by adopting an appropriate FBD rule.

Alternatively, to get a better feel of it we carried out another simulation experiment in which 'Average queue time per job' at manufacturing end was computed. We specifically carried out this experiment for the MAS dispatching rule as we are more focused towards potentials of this FBD rule under different inventory variables. The 'Average queue time per job' for MAS dispatching rule for increasing values of forecasting error is shown in Figure 7. As seen in Figure 7, corresponding to least Average Flow Time (at $\delta_{\varepsilon}=5$ ), MAS shows minimum 'Average queue time per job'. Thus, the appropriate FBD rule at the manufacturing end contributes to mitigate 
the inventory levels in the total SC system that could be caused by demand amplification (bullwhip effect) due to forecasting. To this end, the present research provides a direction for the attenuation of demand amplification viewed from the FBD rules perspective. However, to address the issue of extent by which the effect of demand amplification or bullwhip effect can be mitigated by adopting a specific FBD rule could be the subject for future research.

\section{Pl. Insert Figure 7 about here}

We now report the results concerning re-order point. In this analysis, we carried out two experiments: ROP and NOROP at different values of review period, as mentioned in Section 4.3. Figure 8 (a) and (b) shows that FCFAM dispatching rule outperforms the MAS dispatching rule, irrespective of re-ordering policy (ROP or NOROP) considered in inventory system. However, in case of NOROP, the difference in value of Average Flow time between FCFAM and MAS is comparatively less. From this result, it is apparent to carry out an experiment with increasing values of review period at greater value of forecasting error $\left(\delta_{\varepsilon}=5\right)$. From Figure 8 (c), the correspondence of this result in Figure 6 is clear. The MAS dispatching rule is beneficial at larger values of forecasting error $\left(\delta_{\varepsilon}=5\right)$ irrespective of increase in review period values.

\section{Pl. Insert Figure 8 about here}

We now discuss the results of the experiments that involve back order information. Figure 9 shows that MAS dispatching rule significantly out performs FCFAM with higher information coordination among supply chain holons - there is availability of information of backorders of focal manufacturer and warehouse both (MWINF). Table 3 shows ANOVA conducted with the information coordination at level MWINF. The ANOVA is carried out at a confidence level of $99 \%(\alpha=0.01)$.

\begin{tabular}{cccccc}
\hline Source of variation & Sum squares & DF & Mean squares & F-EXP & F-CRIT \\
\hline FCFAM and MAS & 12.1 & 1 & 12.1 & 74564.62 & 98.503 \\
Error (W. Treatments) & 0.0003245 & 2 & 0.000162 & & \\
Total & 12.1 & 3 & & & \\
\hline
\end{tabular}

Table 3: ANOVA of Average Flow Time for FCFAM and MAS rules in the MWINF case

\section{Pl. Insert Figure 9 about here}

\subsection{Sensitivity analysis - Demand at retailers and information delay of back orders}

The study carried out in Section 5 call for two sensitivity issues: Demand at retailers' end and information delay of back orders. We specifically focus MAS dispatching rule for carrying out sensitivity study. As seen in the analysis of forecasting error factor, benefits are realized in case 
of MAS dispatching rule when the value of forecasting error is high $\left(\delta_{\varepsilon}=5\right)$. This result foresees an issue that if the order size from focal manufacturer is large, MAS dispatching rule over shadows the FCFAM rule. Therefore, we carried out an experiment in which demand at all the retailers was considered with time between arrivals as exponentially distributed (EXPO $(0.1))$. As anticipated, in contrast to result shown in Figure 6, we find that the MAS dispatching rule with Average Flow Time (=0.4298 min.) out performs FCFAM (=1.264 min.) at low values of forecasting error $\left(\delta_{\varepsilon}=1.5\right)$.

Similarly, we carried out an experiment to study the sensitivity of back order information delay on MAS and FCFAM. In this experiment we consider monitoring of back orders for increasing values of time delay. We find that the results were in harmony with the result shown in Figure 9; MAS dispatching rule out performed FCFAM significantly when there is availability of information of backorders of focal manufacturer and warehouse both (MWINF). However, we foresee a sensitivity issue pertaining to review period factor. Therefore, we studied the effect of increasing values of review period on back order information at level MINF and MWINF. Interestingly, at level MINF, FCFAM outperforms MAS at larger value of review period $(=60$ time units) as shown in Figure 10. The ANOVA result shown in table 4 validates the result. However, the results remain unperturbed with the increasing values of review period in case of back order information level MWINF - MAS dispatching rule remains favorable for increasing values of review period in consistent with the result shown in Figure 9.

\begin{tabular}{cccccc}
\hline Source of variation & Sum squares & DF & Mean squares & F-EXP & F-CRIT \\
\hline FCFAM and MAS & 3.831 & 1 & 3.831 & 90802.469 & 98.503 \\
Error (W. Treatments) & 0.0000843 & 2 & 0.0000422 & & \\
Total & 3.831 & 3 & & & \\
\hline
\end{tabular}

Table 4: ANOVA of Average Flow Time for FCFAM and MAS at level MINF with RP=60

\section{Pl. Insert Figure 10 about here}

\section{Discussion of results}

In this paper, we studied the use of two well-known family-based dispatching rules FCFAM and MAS under the premise of differing inventory policies adopted at various supply chain holons. In particular, we conceptualize various informational potentials at intra and inter-holon levels consistent with Holonic paradigm suggested by Koestler (1967). We now discuss the results obtained so as to underline some of the observations that respond to the objectives defined in Section 2 from the FBD rules perspective. The specific focus of study remains, in what situations MAS dispatching rule outperforms the conventional FCFAM rule. In view of this the potential findings of the present paper are:

- The shop load is realized from the order size that each immediate downstream SC holon sends to the upper holon. This provides a more realistic picture while selecting the FBD rule at the manufacturing end.

- MAS dispatching rule shows its potential at high values of shop load caused by larger order size. This is quite intuitive due to the value in the denominator of its relation: Average Flow Time. The threshold, at which the effect of denominator 
shows its potential for a specific FBD rule, greatly depends on the quantity ordered from the downstream echelon which in turn depends upon the operational parameters of the inventory system.

- Given the stochastic nature of various operational units involved in a SC network, simulation plays a more critical role in finding the optimal trade-off among the involved variables (inventory policies, demand patterns, etc.) with the FBD rules.

- Significant improvement of Average Flow Time is possible by strategically employing the suitable FBD rule at the manufacturing end under varying inventory control policies at downstream SC holons. This provides leverage to managers in case of due-date problem in mass customization.

- A considerable benefit is realized if larger numbers of SC holons involves in information sharing.

- Backorder information is greatly affected by the interval of monitoring the inventory level - the review period factor. This result underlines the fact that for the larger review periods, the back orders get depleted by the demand from downstream SC holon. Thus, the shop load decreases and thereby the benefit of the MAS dispatching rule diminish.

- If larger number of SC holons are involved in information sharing the effect of varying review period does not show its potential.

- We find that switching inventory monitoring policy from ROP to NOROP do not contribute to change in results. However, the sensitivity analysis experiment in which a surge in demand is assumed reflects the role of reorder point - due to larger values of demand, the value of the reorder point increases and thereby result large ordering size.

- The reduction in Average Flow Time by adopting MAS dispatching rule with increasing values of forecasting error indirectly shows a significant finding towards mitigation of effect of demand amplification (Bullwhip effect). The 'Average queue time per job' can be apportioned to the holding cost per job in storage, and thus cost saving by adopting a specific FBD rule. However, this issue needs due consideration for analyzing meticulously and can be regarded as option for future research.

\section{Conclusions}

We undertook a case study of a manufacturer involved in manufacturing of automobile parts and generator sets. We explore its outsourcing of components for turning operations to VEs under the purview of FBD rules. Some important conclusions from this case study were obtained which are the novel contributions of this paper from the managerial implication perspective. Therefore, it was suggested to corporate management of the firm to undertake the following:

(i) Contrary to the normal practice of adopting first come first serve rule for prioritizing, the jobs should be grouped into families and the prioritizing decision should be based upon the comparison of FBD rules.

(ii) Instead of realizing shop load locally, the FBD issue should be addressed as the result of inventory replenishment order requirements from the downstream echelons of SC network perspective. This certainly connotes to real life situation while studying the performance of the SC from system wide perspective.

(iii) Although, we had focused on a much smaller distribution network of the firm under study, however, the simulation approach for modeling supply chains provides advantages in development of the generic SC platform. This generic platform is instrumental to take 
on the complexities of multi-echelon interface interactions under inherent SC uncertainties (Wadhwa et al. 2008). Thus, the present SC model provides a generic construct and conceptual directionality to the issue addressed and can be used as a facsimile of any real life industrial SC setup under investigation as well. Thus, the simulation exercise of a wider distribution network of the firm can be undertaken as a future work.

(iv) Educate the benefits of information sharing in terms of improved Average Flow Time performance.

The other future research options includes: (i) the behavior of FBD rules under the premise of uncertainties within and at the interfaces of echelons (e.g., demand, lead times and its standard deviations), (ii) the behavior of FBD rules with the change in number of virtual enterprises and/or routing flexibility of families to VEs, (iii) the behavior of FBD rules for other SC structures, and (iv) the degree to which the appropriate FBD rules are beneficial in mitigation of unconstructive cost related to consequences of demand amplification i.e., Bullwhip effect.

\section{References}

1. Cachon, G.P., \& Fisher, M. (2000). Supply chain inventory management and the value of shared information. Management Science, 46(8), 1032-1048.

2. Chang, Y., \& Makatosoris, H. (2001). Supply chain modelling using simulation. International Journal of Simulation, 2(1), 24-30.

3. Chen, F. (1998). Echelon reorder points, installation reorder points, and the value of centralized demand information. Management Science, 44(2), 1221-1234.

4. Chen, Y.M., Liao, C.C., \& Prasad, B. (1998). A systematic application of virtual enterprising through knowledge management techniques. Journal of Concurrent Engineering Research and Application, 6(3), 225-244.

5. Christopher, M., \& Towill D. (2001). An integrated model for the design of agile supply chains. International journal of physical distribution logistic management, 31(4), 235246.

6. Christopher, M., \& Lee, H. (2004). Mitigating supply chain risk through improved confidence. International Journal of Physical Distribution and Logistics Management, 34(5), 388-396.

7. Dev, N.K., Caprihan, R., \& Swami, S. (2011). A case study of redesign of supply chain network of a manufacturing organization. Journal of Advances in Management Research, $8(2), 195-212$.

8. Dev, N.K., \& Shankar, R. (2012). Design of fractal information coordination system in a supply chain network. International Journal of Services and Operations Management, 12(1), 1-19.

9. Dev, N.K., Caprihan, R., \& Swami, S. (2012). Strategic positioning of push-pull boundary within a supply chain: An ordering policy co-ordination perspective. Operations and Supply Chain Management, 5(1), 42-53. 
10. Dominici, G. (2008). Holonic Production System to Obtain Flexibility for Customer Satisfaction. Journal of Service Science and Management, 1(3), 251-254.

11. Fernando, J.M.M., \& Sichman, J.S. (2010). Oil industry supply chain management as a holonic agent based distributed constraint optimization problem. In proceedings of $19^{\text {th }}$ European conference on Artificial intelligence, August 17, 2010, Lisbon, Portugal.

12. Fletcher, M., Garcia-Herreros, E., Christensen, J. H., Deen, S. M., \& Mittman, R. (2000). An open architecture for holonic cooperation and autonomy. In Proceedings of $11^{\text {th }}$ international Workshop on Database and Expert Systems Applications, pp. 224-230.

13. Frazier, G.V. (1996). An evaluation of group scheduling heuristics in a flow-line manufacturing cell. International Journal of Production Research, 34(4), 959-976.

14. Georges, M.R.R., Franco, G.N., \& Batocchio, A. (2009). Extending holonic manufacturing systems to achieve the virtual supply chain domain. Journal of Operations and Supply Chain Management, 2(2), 47-55.

15. Goletz, T., \& Ferreira, J.J.P. (2000). Enacting dynamic distribution networks - the DAMASCOS project. In: Camarinha-Matos, L.M., Afsarmanesh, H., Erbe, H. (Eds.), Advances in Networked Enterprises - Virtual Organizations, Balanced Automation and Systems Integration. Kluwer Academic Publishers, Dordrecht, 73-80.

16. Gupta, D. (1996). The (Q, R) inventory system with an unreliable supplier. INFORM 34(2), 59-76.

17. Hamedi, M., Esmaeilian, G.R., Ismail, N., \& Ariffin, M.K.A. (2012). Capability-based virtual cellular manufacturing systems formation in dual-resource constrained settings using Tabu search. Computers and Industrial Engineering, 62, 953-971.

18. Huang, B., Gou, H., Liu, W., Li, Y., \& Xie, M. (2002). A framework for virtual enterprise control with the holonic manufacturing paradigm. Computers in Industry, 49(3), 299-310.

19. Kannan, V. R., \& Ghosh, S. (1996). Cellular manufacturing using virtual cells. International journal of operations and production management, 16(5), 99-112.

20. Kara, S., \& Kayis, B. (2004). Manufacturing flexibility and variability: An overview. Journal of Manufacturing Technology Management, 115(6), 466-478.

21. Kelton, W.D., Sadowski, R.P., \& Swets, N.B. (2010). Simulation with Arena. $5^{\text {th }}$ ed. New York: McGraw-Hill.

22. Ko, H.H., Kim, J., Kim, S.S., \& Baek, J.G. (2010). Dispatching rule for non-identical parallel machines with sequence-dependent setups and quality restrictions. Computers and Industrial Engineering, 59, 448-457.

23. Koestler, A. (1967). The ghost in the machine. Arkana, London.

24. Kotak, D., Wu, S., Fleetwood, M., \& Tamoto, H. (2003). Agent-based holonic design and operation environment for distributed manufacturing. Computers in Industry, 52(2), 95108.

25. Lau, R.S.M., \& Yam, R.C.M. (2005). A case study of product modularization on supply chain design and coordination in Hong Kong and China. Journal of manufacturing technology management, 16(4), 432-446. 
26. Lewis, B. (2005). Inventory control with risk of major supply chain disruptions. Ph.D. thesis, Georgia Institute of Technology.

27. Li, X., \& Y. Chen. (2010). Impacts of supply disruptions and customer differentiation on a partial-backordering inventory system. Simulation Modelling Practice and Theory, $18(5), 547-557$.

28. Little, J. (1961). A proof of the queuing formula $\mathrm{L}=\lambda * \mathrm{~W}$. Operations Research, 9, 383387.

29. Longo, F., Mirabelli, G., \& Papoff, E. (2005). Modelling analysis and simulation of a supply chain devoted to support pharmaceutical business retail. In the proceedings of $18^{\text {th }}$ International Conference on Production Research, Salerno, Italy.

30. Mahmoodi, F., Tierney, E.J., \& Mosier, C.T. (1992). Dynamic group scheduling heuristics in a flow-through cell environment. Decision Sciences, 23(1), 61-85.

31. Mahmoodi, F., \& Martin, G.E. (1997). A new shop-based and predictive scheduling heuristic for cellular manufacturing. International Journal of Production Research, 35(2), 313-326.

32. Masuchun, W., Davis, S., \& Patterson, J.W. (2004). Comparison of push and pull control strategies for supply network management in a make-to-stock environment. International Journal of Production Research, 42(20), 4401-4419.

33. Mohebbi, E. (2004). A replenishment model for the supply-uncertainty problem. International Journal of Production Economics, 87(1), 25-37.

34. Mosier, C.T., Elvers, D.A., \& Nelly, D. (1984). Analysis of group technology scheduling heuristics. International Journal of Production Research, 22(5), 857-875.

35. Narasimhan, R., \& Carter, J.R. (1998). Linking business unit and material sourcing strategies. Journal of Business Logistics, 19(2), 155-171.

36. Nomden, G., Van Der, D.J., \& Slomp, J. (2008). Family-based dispatching: anticipating future jobs. International journal of Production Research, 46(11), 73-97.

37. Olhager, J., \& Persson, F. (2006). Simulating production and inventory control system: A learning approach to operational excellence. Production Planning and Control, 17(2), 113-127.

38. Sahin, F., \& Robinson, E.P. (2002). Flow coordination and information sharing in supply chain: review, implications, and directions for future research. Decision Sciences, 33(4), 505-536.

39. Samvedi, A., \& Jain, V. (2011). Studying the impact of various inventory policies on a supply chain with intermittent supply disruptions. In the proceedings of the 2011 Winter Simulation Conference, Phoenix, AZ, 1641-1649.

40. Sensi, G. De, Longo, F., \& Mirabelli, G. (2008). Inventory policy analysis under demand patterns and lead times constraints in a real supply chain. International Journal of Production Research, 46(24), 6997-7016.

41. Sheffi, Y., \& Rice, J. B. (2005). A supply chain view of the resilient enterprise. MIT Sloan Management Review, 47(1), 41-48. 
42. Sihn, W. (1998). Manufacturing in networks-competitive advantages for virtual enterprise. In the proceedings of the International Conference of Manufacturing ValueChain, Troon, Scotland.

43. Suda, H. (1989). Future factory system formulated in Japan. Japanese Journal of Advanced Automation Technology, 1(1), 15-25.

44. Suwanruji, P., \& Enns, S.T. (2006). Evaluating the effects of capacity constraints and demand patterns on supply chain replenishment strategies. International Journal of Production Research, 44(21), 4607-4629.

45. Tang, C.S. (2006). Perspectives in supply chain risk management. International Journal of Production Economics, 103(2), 451-488.

46. Thomas, D.J., \& Griffin, P.M. (1996). Coordinated supply chain management. European Journal of Operations Research, 94(1), 1-15.

47. Van Brussel, H., Valckenaers, P., Bongaerts, L., \& Wyns, J. (1995). Architectural and systems design issues in holonic manufacturing systems. In Proceedings of the $3^{\text {rd }}$ IFAC/ IFIP/IFORS Workshop on Intelligent Manufacturing Systems IMS'95, 1-6.

48. Van der Zee, D.-J. (2013). Family based dispatching with batch availability. International Journal of Production Research, 51(12), 3643-3653.

49. Vernadat, F.B. (1997). Enterprise Modeling and Integration: Principles and Applications. London, U.K.: Chapman \& Hall.

50. Wadhwa, S., Mishra, M., Chan, F.T.S., \& Ducq, Y. (2008). Effects of information transparency and cooperation on supply chain performance: a simulation study. International Journal of Production Research, 48(1), 145-166.

51. Winkler, H. (2009). How to improve supply chain flexibility using strategic supply chain networks. Logistics Research, 1(1), 15-25. 


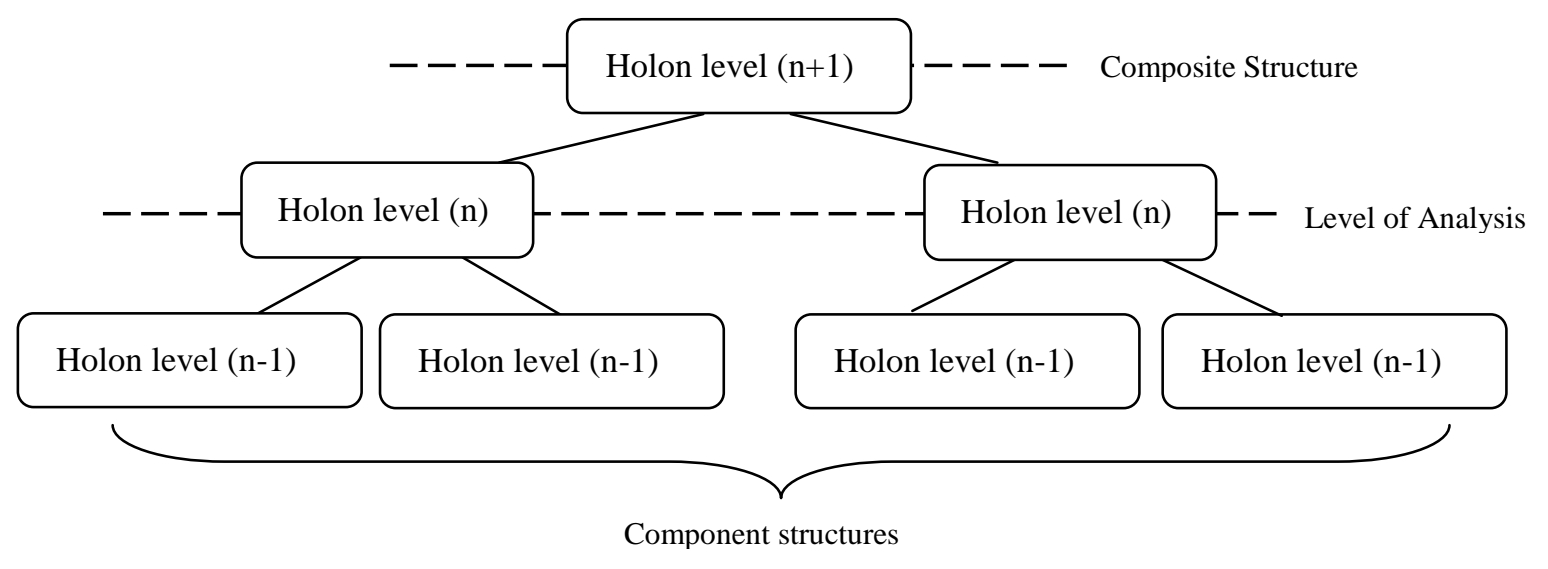

Figure 1: Holons and Holarchies (Source: Winkler, 2009)

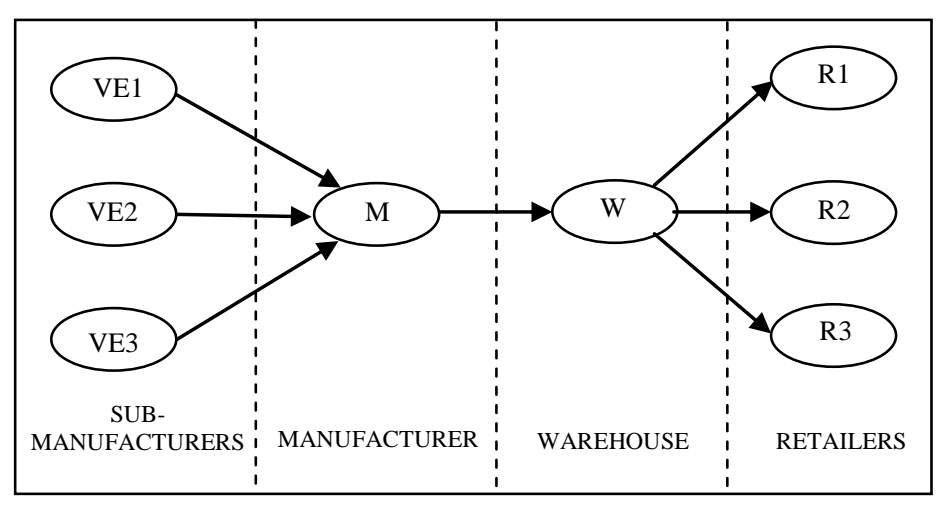

Figure 2: Supply chain network structure 


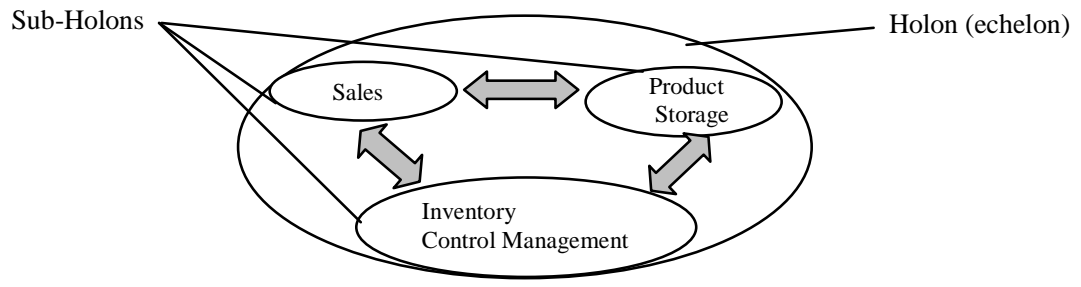

Figure 3: Operations performed within a holon (echelon)

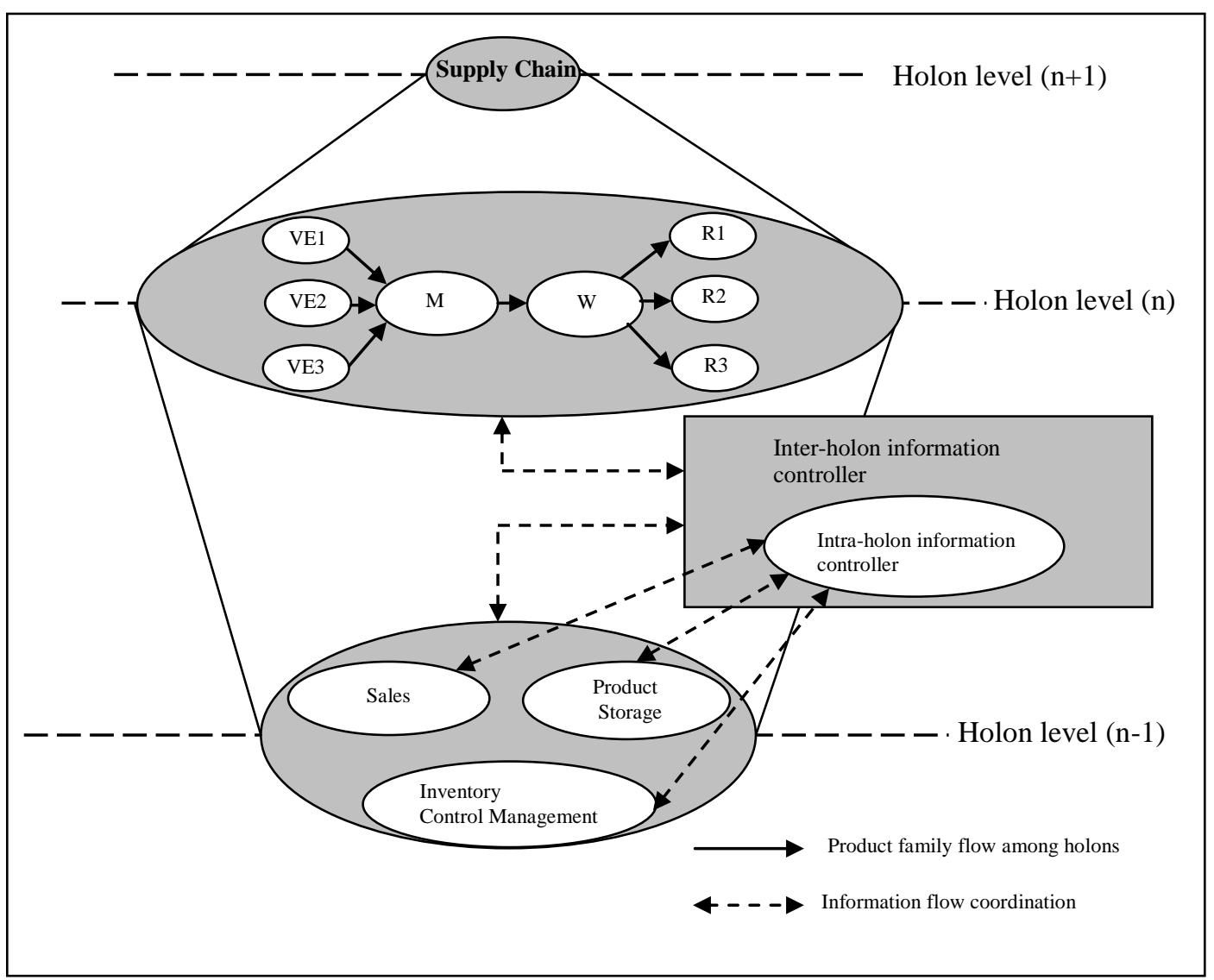

Figure 4: SC holarchy at different levels for simulation study 


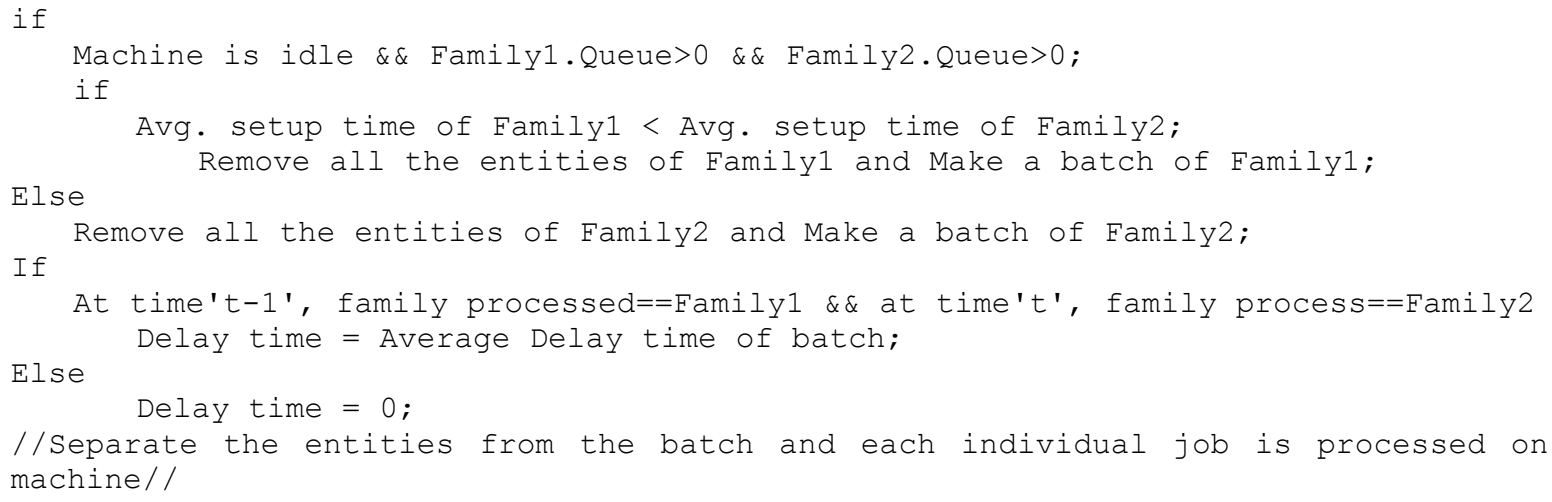

Figure 5: Algorithm of information holon model for MAS in simulation

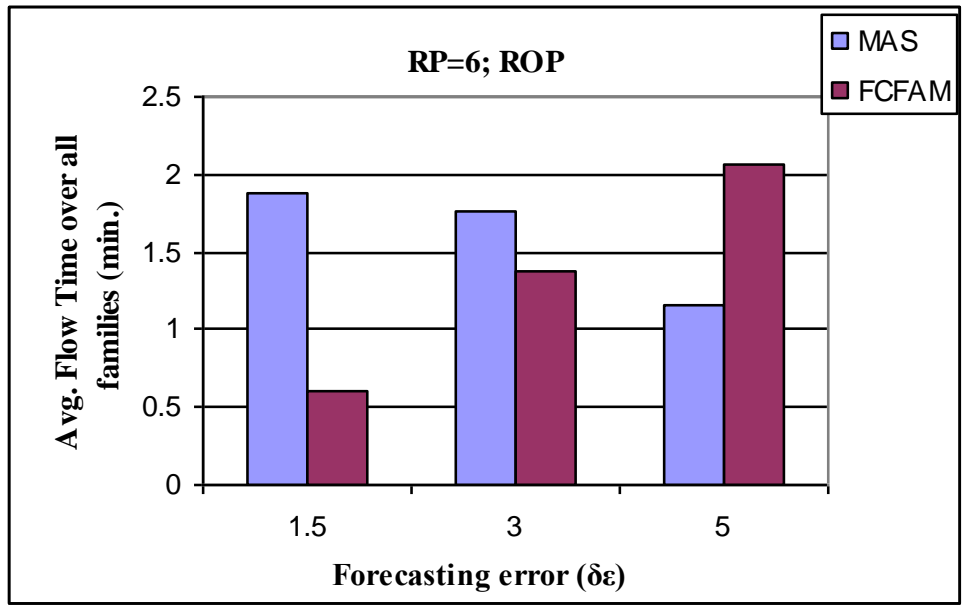

Figure 6: Comparison of FCFAM and MAS with increasing values of forecasting error ' $\delta_{\varepsilon}$ ' 


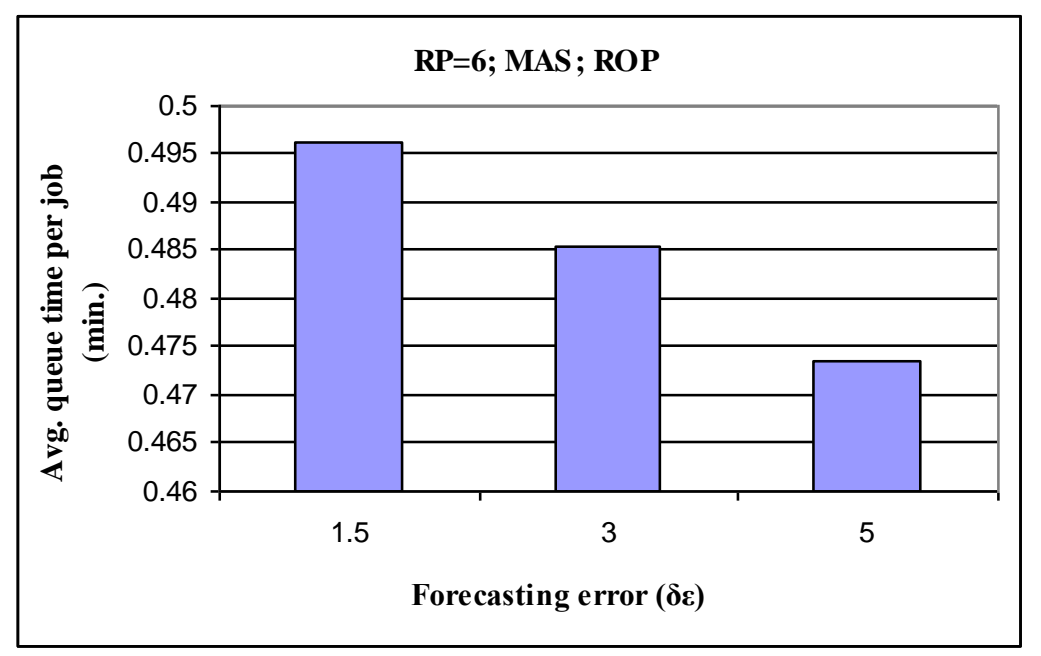

Figure 7: Average queue time per job for MAS dispatching rule

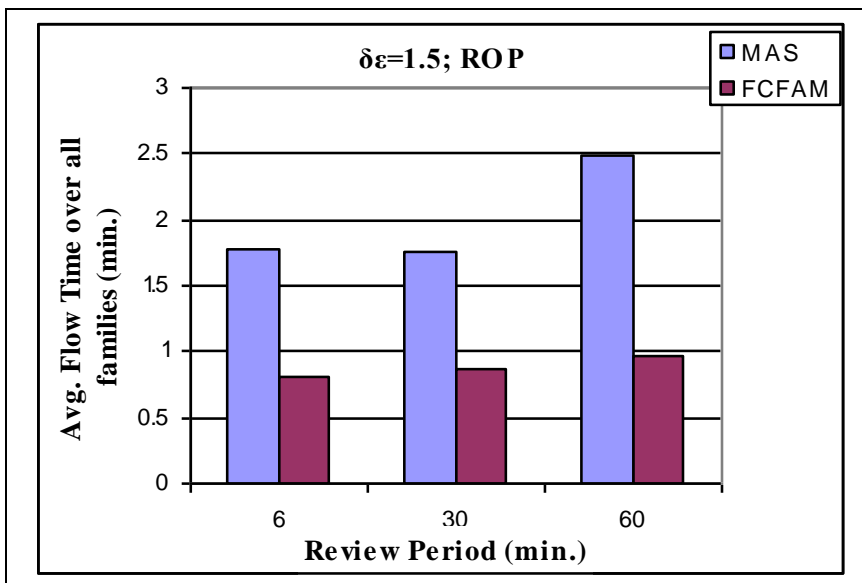

(a)

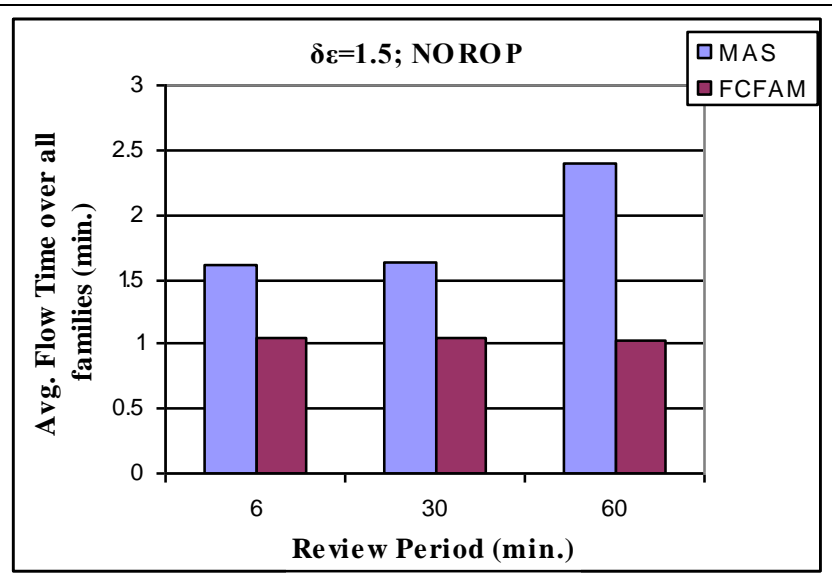

(b)

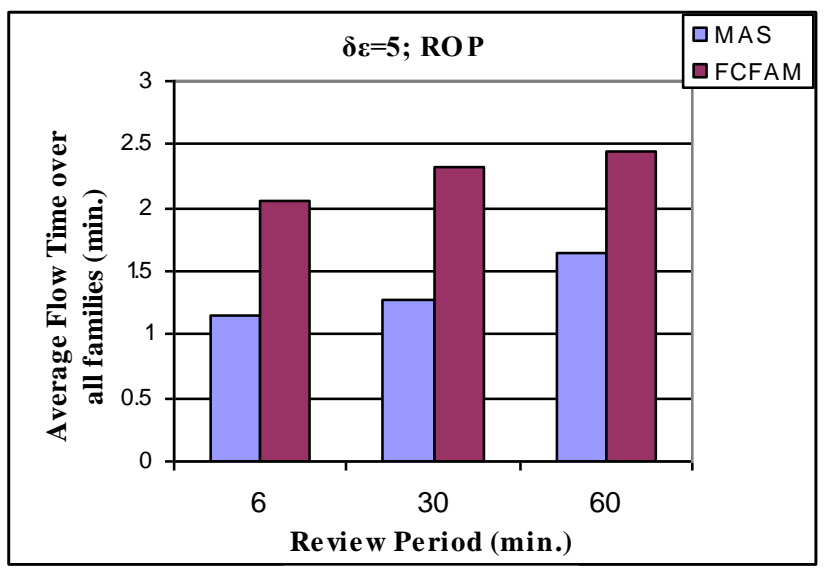

(c)

Figure 8: Average Flow Time at different review periods for (a) ROP, (b) NOROP case and (c) ROP with $\left(\delta_{\varepsilon}=5\right)$ 


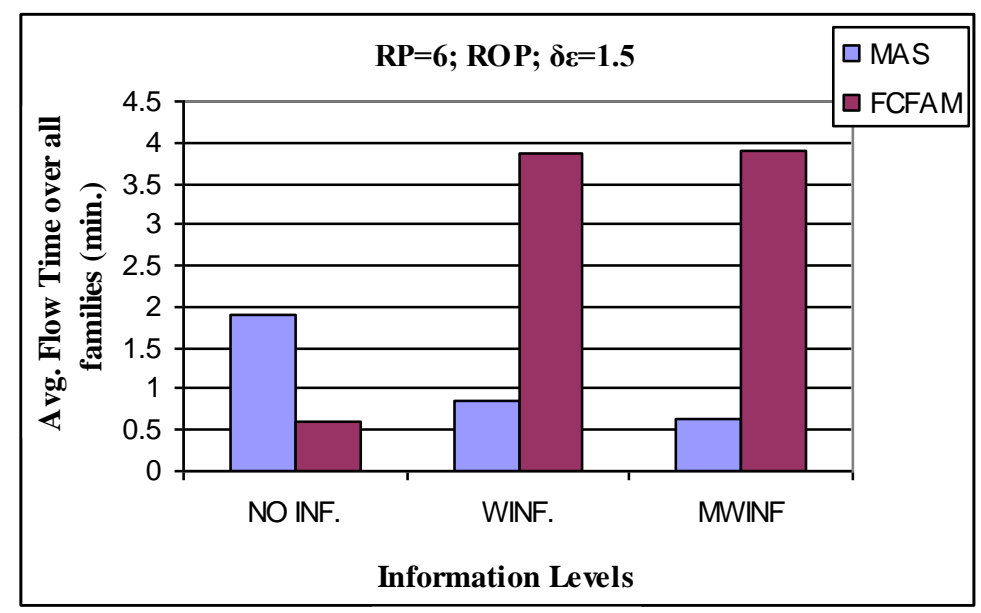

Figure 9: Average Flow Time at different levels of back order information

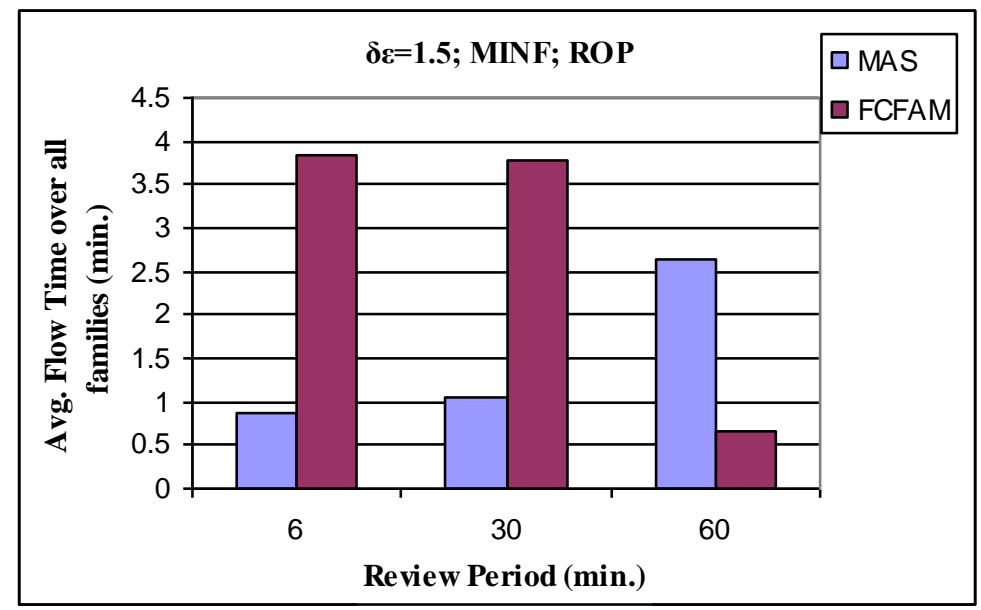

Figure 10: Average Flow Time at different review periods for the level MINF 


\begin{tabular}{|c|c|}
\hline Fixed Factors & \\
\hline No. of families & 03 \\
\hline Holarchy levels (No. of Echelons) - 04 & $\begin{array}{l}\text { 3-Retailers; } \\
\text { 1-Warehouse; } \\
\text { 1-Focal Manufacturer; } \\
\text { 3-VEs }\end{array}$ \\
\hline Demand at 3-Retailers (D) & Time between Arrival = $\operatorname{EXPO}(0.5)$ \\
\hline Minor Set-up time distribution & $\operatorname{NORM}(5,0.2)$ \\
\hline Processing time distribution & $\operatorname{NORM}(1,0.2)$ \\
\hline Orders from $(\mathrm{M})$ to $\mathrm{VE}$ & $\begin{array}{l}\text { Family1 - Randomly to VE1 and VE2 } \\
\text { Family2 - Randomly to VE2 and VE3 } \\
\text { Family3 - Randomly to VE3 and VE1 }\end{array}$ \\
\hline Information delay of back orders & $1 \mathrm{~min}$. \\
\hline Experimental Factors & \\
\hline Family-based dispatching rules $(\mathrm{R})$ & FCFAM and MAS \\
\hline Forecast error (FE) & $\mathrm{FE}=1.5^{*} \mathrm{D} ; 3 * \mathrm{D} ; 5^{*} \mathrm{D}$ \\
\hline Review Period (RP) in min. & $\mathrm{RP}=6 ; 30 ; 60$ \\
\hline Information of back orders of echelons & $\begin{array}{l}\text { No information of Back orders (NOINF); } \\
\text { Manufacturer back orders information (MINF); } \\
\text { Manufacturer and Warehouse back orders information (MWINF) }\end{array}$ \\
\hline Inventory policy & $\begin{array}{l}\text { ROP = After Review Period, Order if inventory level touches ROP; } \\
\text { NOROP = Order after each review period irrespective of ROP }\end{array}$ \\
\hline
\end{tabular}

Table 1: Overview of experimental factors and levels

\begin{tabular}{cccccc}
\hline Source of variation & Sum squares & DF & Mean squares & F-EXP & F-CRIT \\
\hline FCFAM and MAS & 1.255 & 1 & 1.255 & 5009.933 & 98.503 \\
Error (W. Treatments) & 0.000495 & 2 & 0.000248 & & \\
Total & 1.255 & 3 & & & \\
\hline
\end{tabular}

Table 2: ANOVA of Average Flow Time for FCFAM and MAS rules at $\delta_{\varepsilon}=1.5$

\begin{tabular}{cccccc}
\hline Source of variation & Sum squares & DF & Mean squares & F-EXP & F-CRIT \\
\hline FCFAM and MAS & 12.1 & 1 & 12.1 & 74564.62 & 98.503 \\
Error (W. Treatments) & 0.0003245 & 2 & 0.000162 & & \\
Total & 12.1 & 3 & & & \\
\hline
\end{tabular}

Table 3: ANOVA of Average Flow Time for FCFAM and MAS rules in the MWINF case 


\begin{tabular}{cccccc}
\hline Source of variation & Sum squares & DF & Mean squares & F-EXP & F-CRIT \\
\hline FCFAM and MAS & 3.831 & 1 & 3.831 & 90802.469 & 98.503 \\
Error (W. Treatments) & 0.0000843 & 2 & 0.0000422 & & \\
Total & 3.831 & 3 & & & \\
\hline
\end{tabular}

Table 4: ANOVA of Average Flow Time for FCFAM and MAS at level MINF with RP=60 


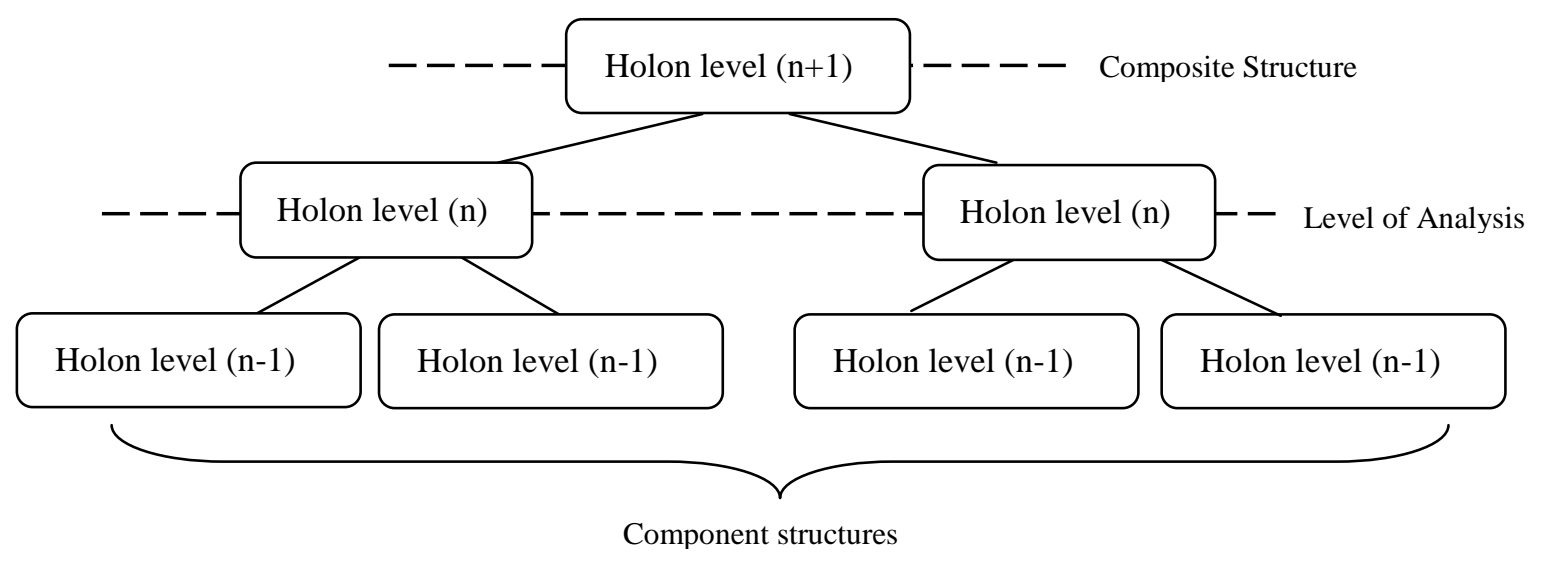

Figure 1: Holons and Holarchies (Source: Winkler, 2009)

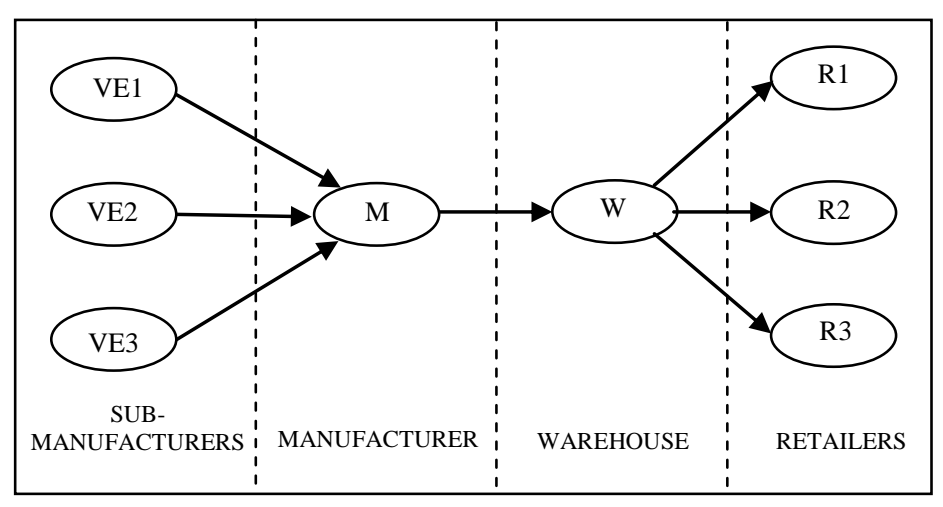

Figure 2: Supply chain network structure 


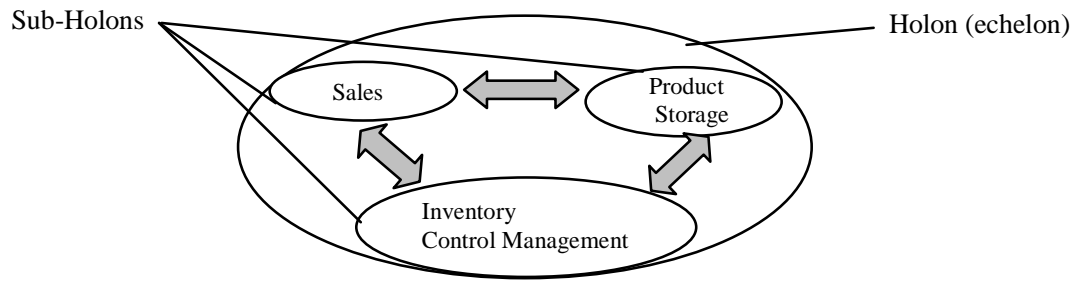

Figure 3: Operations performed within a holon (echelon)

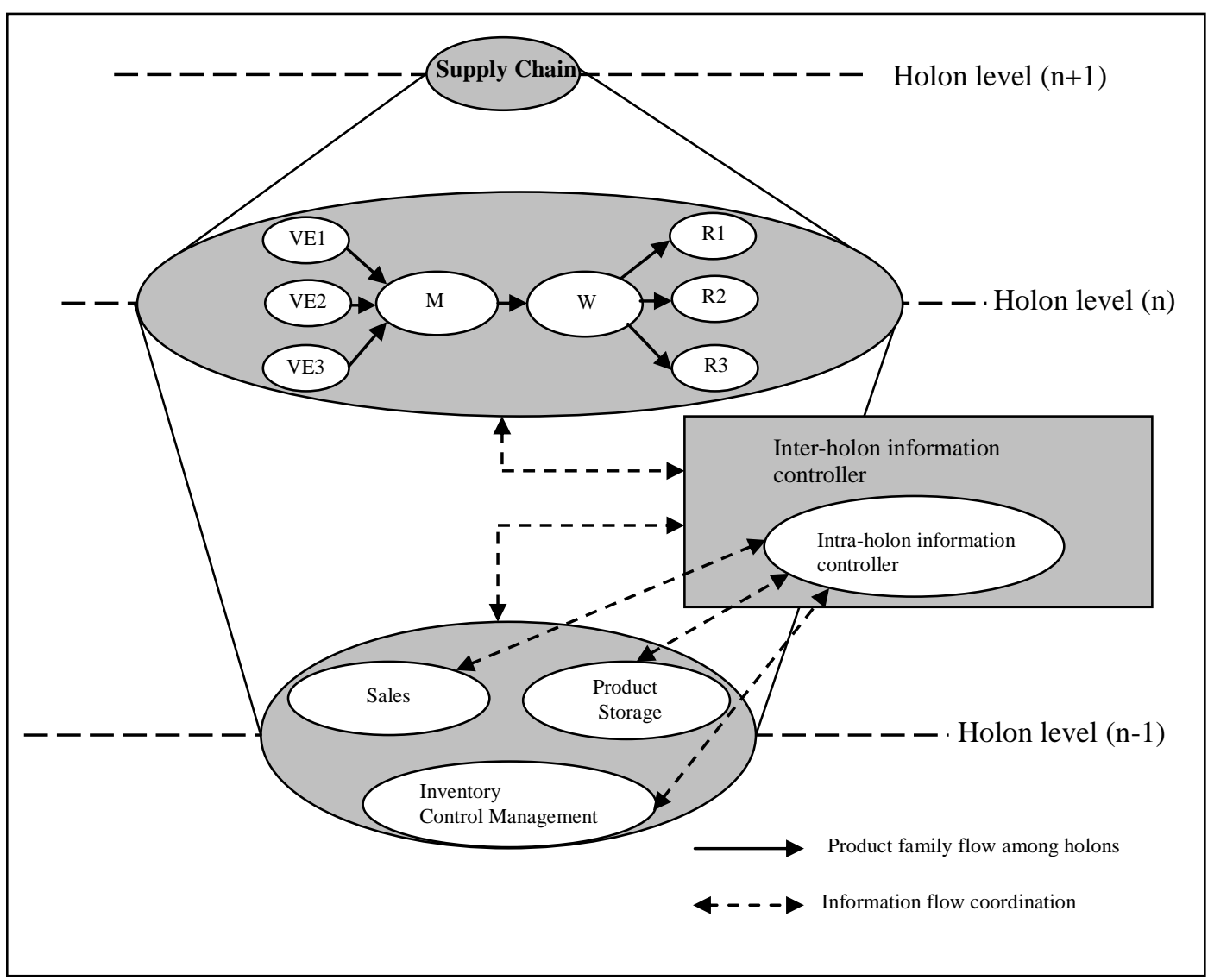

Figure 4: SC holarchy at different levels for simulation study 


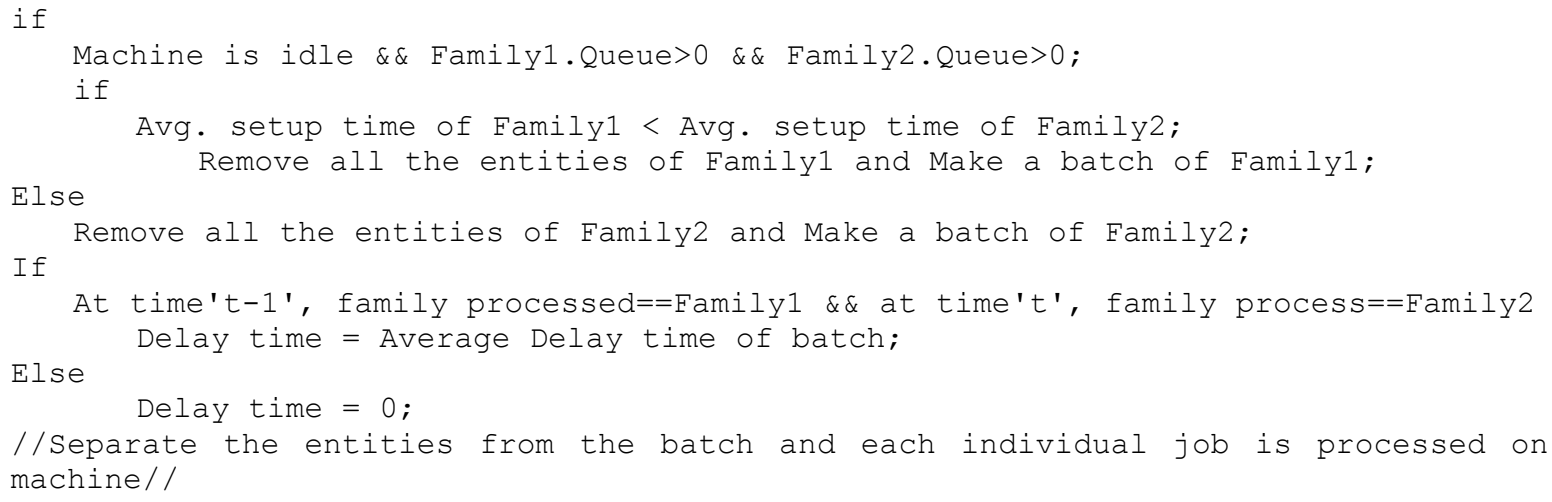

Figure 5: Algorithm of information holon model for MAS in simulation

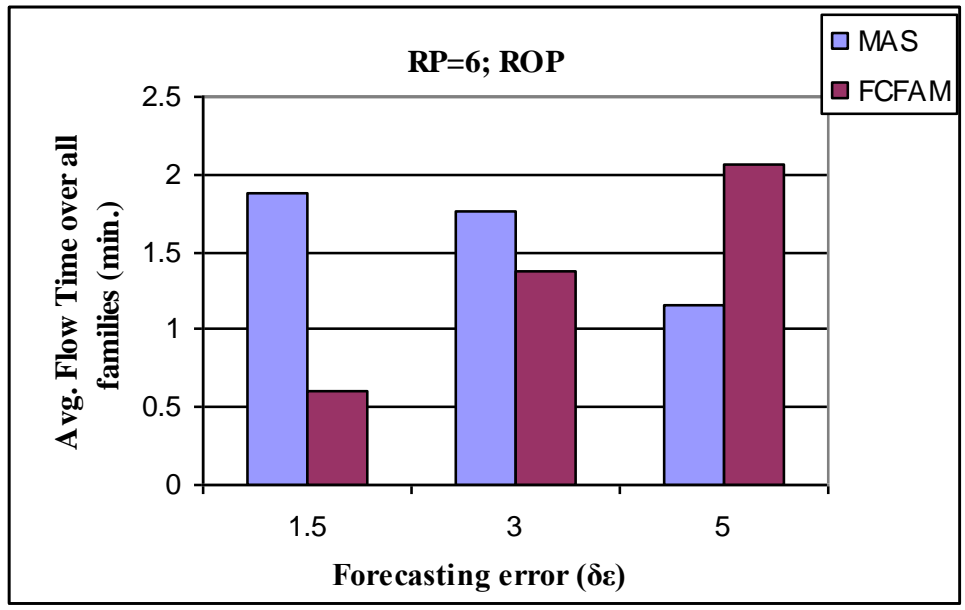

Figure 6: Comparison of FCFAM and MAS with increasing values of forecasting error ' $\delta_{\varepsilon}$ ' 


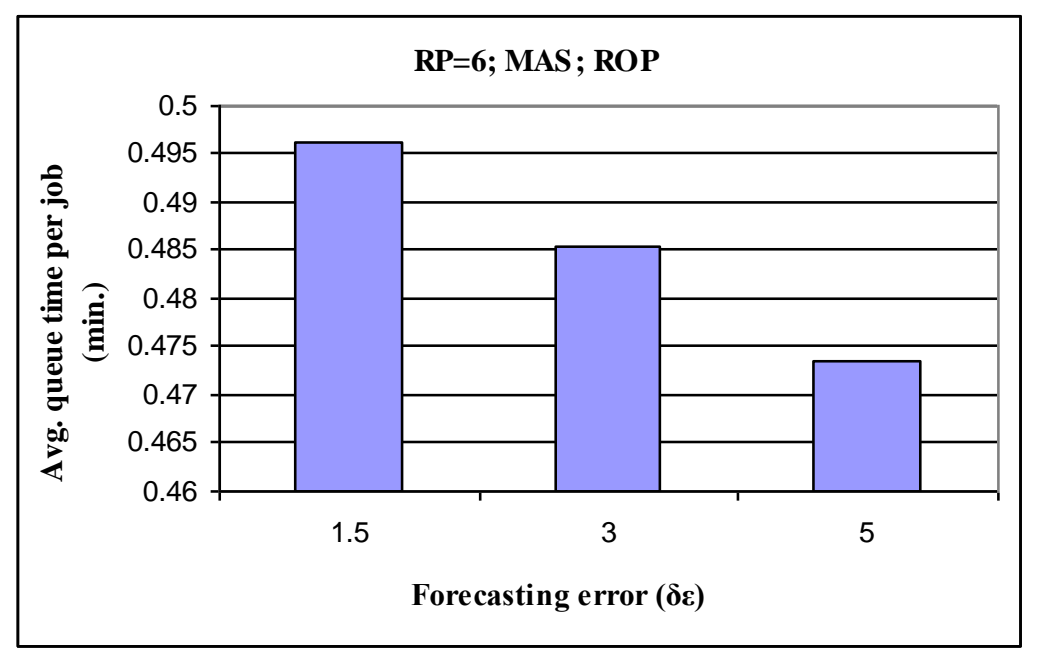

Figure 7: Average queue time per job for MAS dispatching rule

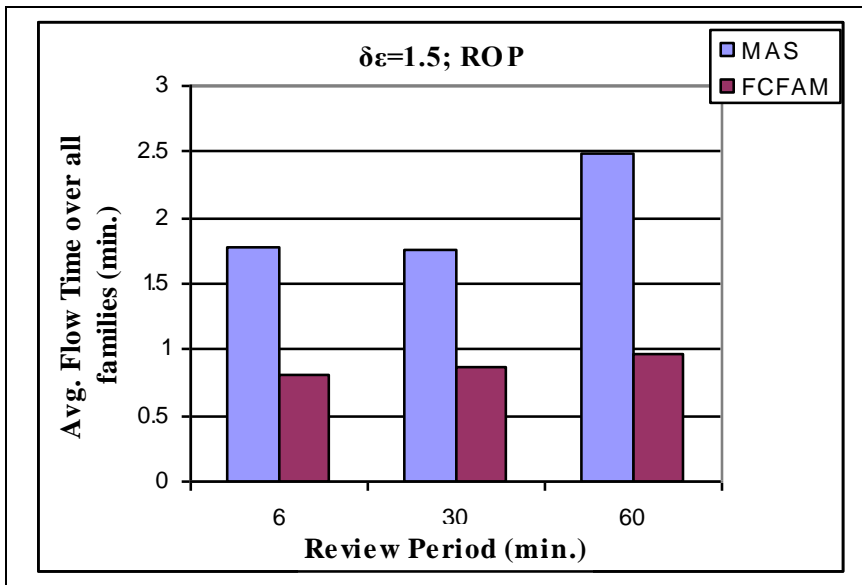

(a)

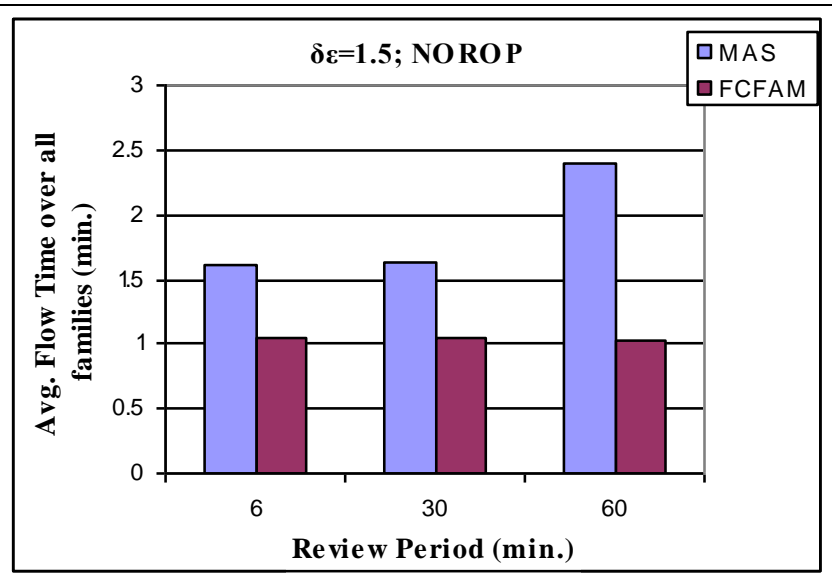

(b)

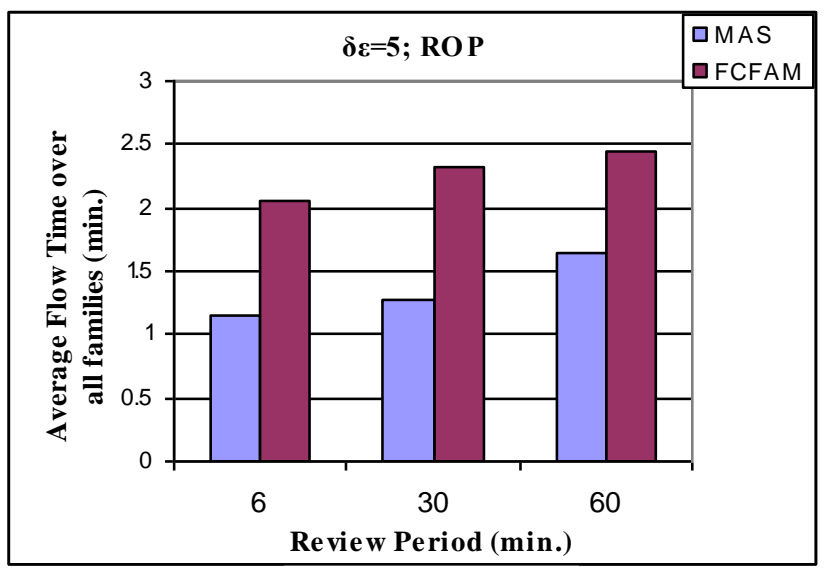

(c)

Figure 8: Average Flow Time at different review periods for (a) ROP, (b) NOROP case and (c) ROP with $\left(\delta_{\varepsilon}=5\right)$ 


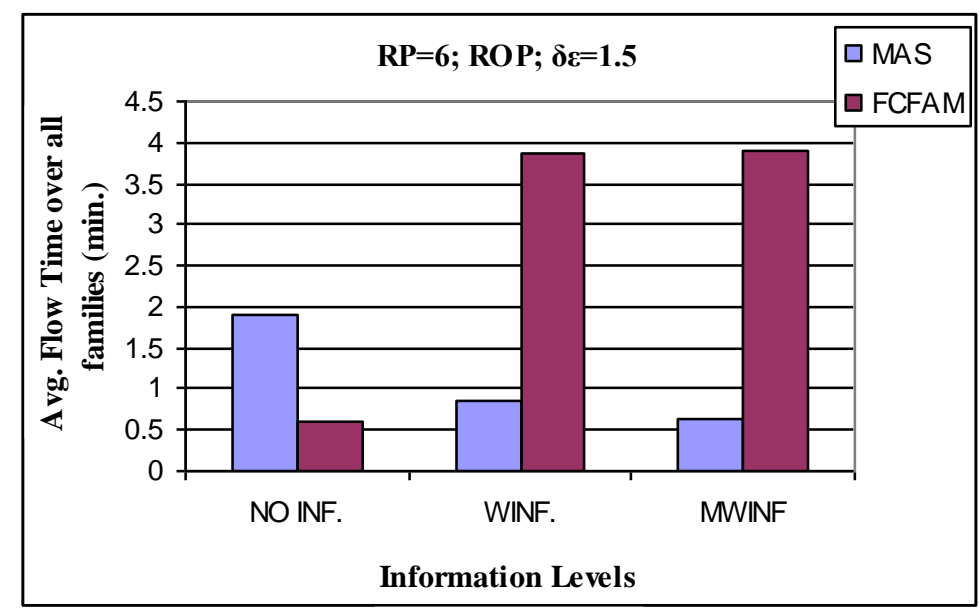

Figure 9: Average Flow Time at different levels of back order information

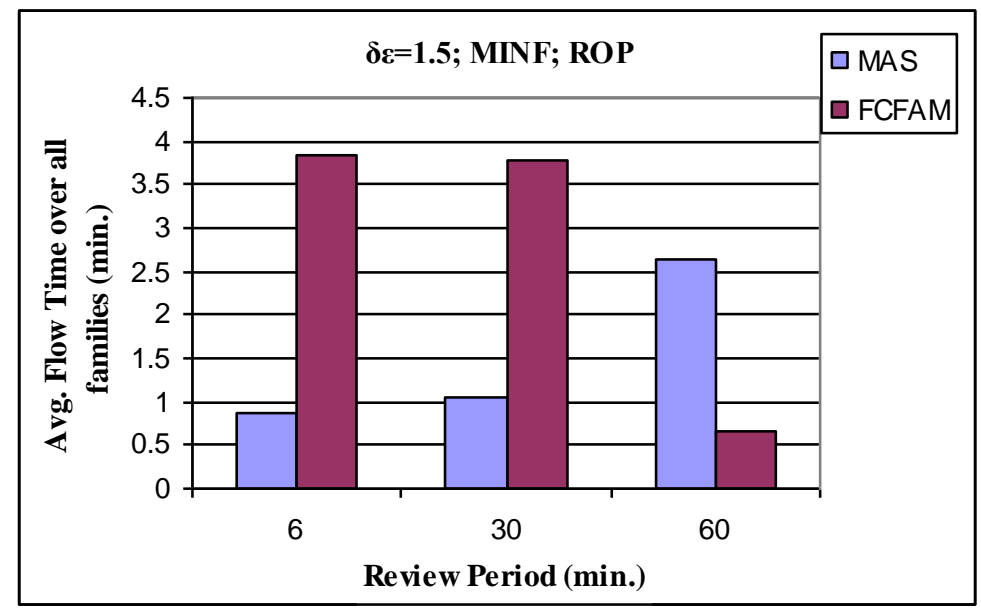

Figure 10: Average Flow Time at different review periods for the level MINF 


\section{Acknowledgement}

The authors acknowledge all the reviewers for their indispensable inputs, comments, and suggestions that improved this article significantly. 